\title{
Specialization in offending: A comprehensive review of criminological theories and empirical studies
}

\author{
Ahmet Eker ${ }^{1}$ \\ Ekrem Mus ${ }^{2}$
}

\begin{abstract}
Policy makers, legislators, and law enforcement practitioners generally believe that criminals do specialize in offending and they commit only one type of crime throughout their criminal career. Criminal laws, crime prevention programs, and criminal investigation techniques have been shaped by this assumption. On the other hand, a perennial debate amongst criminologists and researchers shows whether criminals have a tendency of specialization or versatility. Some theorists claim that there is one underlying reason for deviance; thus, offenders commit all available crimes. Whereas, others argue that offenders commit crimes for different reasons and needs. As a result, they have a tendency of specialization. Conversely, developmental criminologists claim both specialization and versatility. In this paper, we will start by explaining the theoretical assumptions and results of empirical studies regarding the effects of age, gender, peers, and crime types on offence specialization. Later, we will discuss the assumptions of the theories in the light of the related researches. Finally, we will present various policy and the research recommendations of this study.
\end{abstract}

Keywords: Specialization; Versatility; Criminal Career; Sex Crime; Violent/Non-Violent Crimes; Life-Course.

\section{Introduction}

Most of the policy and law makers, practitioners, and even the general public generally believe that "offenders become skilled at one particular crime and continue to commit that crime with great frequency and ease" (Jennings et al., 2014:184). This manner of excessively committing one type of crime has been formulized by criminologists as "specialization in crime" (Tumminello et al., 2013:2). The "notion of specialization in criminal offending refers to the extent to which an offender tends to repeat the same specific offense or offense type on successive criminal events" (Paternoster et al., 1998:133; Britt, 1996; Lussier \& Cale, 2013: 452). Many theorists, such as Cloward and Ohlin, and Sutherland, supported this notion. Hence, they argue that the "lack of legitimate opportunities" and "learning process through interactions" with other criminals lead to "specialization in specific types of crimes" (Jennings et al., 2014:185; Tumminello et al., 2013:2). Furthermore, numerous researchers found evidence of specialization as a result of their empirical studies (Farrington, Snyder \& Finnegan, 1988; Lattimore, Visher \& Linster, 1994; Armstrong \& Britt, 2004; Colvin \& Pauly, 1983).

\footnotetext{
${ }_{1}^{1}$ Ph.D., Chief of Arakli Police Department, Trabzon, Turkey; ahmet.eker.1973@gmail.com

2 Associate Professor, Harran University, Sanluurfa, Turkey; ekremmus@gmail.com
} 
Eker, A., \& Mus, E. (2016). Specialization in offending: A comprehensive review of criminological theories and empirical studies. International Journal of Human Sciences, 13(1), 2295-2322. doi:10.14687/ijhs.v13i1.3760

On the other hand, several leading criminologists, such as Gottfredson, Hirschi, Sampson, and Laub do not agree with this common belief and claim "that offenders infrequently specialize" in crime (Richards et al., 2013:646). Subsequently, criminologists who are "in favor of offender versatility" (Jennings et al., 2014:185) argue that "empirical results that support the existence of crime specialization are admittedly weak". Also, they "suggest that offenders are generalists, who commit" different types of available crimes "due to low level of social control and low self-control" (Tumminello et al., 2013:2). Moreover, preponderance of the researchers (DeLisi, 2003; DeLisi et al., 2011; Mazerolle et al., 2000; Miethe et al., 2006; Nieuwbeerta, Blokland, Piquero, \& Sweeten, 2010; Piquero, 2000; Piquero, Paternoster, Brame, Mazerolle, \& Dean, 2000) discovered that criminals are "usually versatile, not specialized" (as cited by Jennings et al., 2014:185).

In addition to the above debate, several researchers who accept developmental theories claim that offenders' behaviors are not that simple because they are affected by different variables throughout their life. Thus, they present "a combination of specialized and generalized criminal behaviors" (Richards et al., 2014:646). For example, Moffitt (1993) classifies offenders as "adolescence-limited offenders described as primarily committing nonviolent crimes"; and "lifecourse persistent offenders" who "commit a range of crimes" as they get older throughout their long criminal career (Richards et al., 2014:646). In contrast, Piquero et al. (1999) and McGloin et al. claim that older criminals tend to commit the same type of crimes and reduce "offending versatility" while they reduce "offending frequency" (2011:362). Additionally, other researchers "observed that property crimes were conducted with more consistent specialization than violent crimes (Richards et al., 2014:647).

However, an enduring debate continues amongst criminologists regarding "whether some offenders commit a disproportionately large number of the same type of crime during their criminal career and whether this tendency is accentuated over time" (Tumminello et al., 2013:1). A great number of criminologists and researchers argue that "criminal specialization/versatility" debate is "more complicated than was previously thought" (Jennings et al., 2014:185). Hence, they are complicated "both theoretically and methodologically" (Tumminello et al., 2013:2), which include classification of "crime categories, portion of career examined, and method of measurement" (Kempf, 1987:403). Moreover, Mazerolle et al. criticize almost a century old specialization researches for not having "solid theoretical grounding" and "mostly examining very general issues" rather than "examining offense specialization for certain groups differentiated by gender, race, and age" (2000:1144).

The above mentioned debates and researches highlight that determining "whether offenders specialize in a certain crime" and "understanding why specialization does or does not occur" is a "central problem for criminology as well as crime prevention, selective detention, and targeted treatment" policies because a great amount of effort, time, manpower, and budget is devoted to fulfill these policies (Guerette, Stenius \& McCloin, 2005:86; Tumminello et al., 2013:2). For example, policy makers and lawmakers in almost all of the cities of the United States "issued Sex Offender Registration and Notification (SORN) laws". This is based on "a fundamental assumption of specialization among sex offenders" with the aim of reducing the re-occurrence of sex offences (Jennings et al., 2014:184). However, Tewksbury, Jennings and Zgoba claim that this assumption is not accurate because previous research demonstrated that "sex offenders have relatively low rates of recidivism, typically significantly lower than non-sex offenders" (2012:324). Moreover, as a result of their empirical study, they found that "registration and public notifications of identities, characteristics, and residential locations of sex offenders" has only "little effect on reducing/deterring sexual recidivism and reducing/deterring recidivism in general" (2012:310, 324).

Furthermore, other researchers warn policy makers and practitioners because this "premature" but general assumption of specialization in offending has been shaping the police investigation techniques, criminal profiling, and crime analyzing strategies. For example, when the police investigate sex crime, burglary, or robbery, they usually look for the criminals who had committed those crimes hitherto; most especially, they look for the criminals who use the same 
Eker, A., \& Mus, E. (2016). Specialization in offending: A comprehensive review of criminological theories and empirical studies. International Journal of Human Sciences, 13(1), 2295-2322. doi:10.14687/ijhs.v13i1.3760

techniques over and over again (Klein, 1984). Nevertheless, as seen in the case of SORN laws, policy makers, legislators, and practitioners, who generally believe that criminals specialize in certain crimes, should be very careful while they are shaping their crime policies. Thus, this is because vast majority of the criminologists do not "support the notion of specialization" (Klein, 1984; Jennings et al., 2014:185).

This paper tries to inform the decision makers regarding specialization/versatility issue to prevent them from allocating "resources of public" to ineffective policies. In this regard, theoretical assumptions, findings of scientific studies, and policy recommendations will be presented in this paper. First, we will present the assumptions of leading criminological theories. The reasons that they either support or oppose specialization in offending will be mentioned. Second, results of empirical studies will be mentioned. Effects of age, gender, and peers on offending specialization will be presented. Later, we will try to clarify whether offenders specialize in certain crime types, such as violent crimes, non-violent crimes, or sex crimes. Finally, we will discuss the assumptions of criminological theories and the findings of researches and present recommendations for future studies. In addition, we will also present policy recommendations to reduce the level of crime.

\section{Theoretical Assumptions}

Researches on whether criminals focus mostly on same types of crimes (specialization) or commit many different types of crimes (versatility) has important contribution to crime theories which try to explain the underlying reasons of criminal acts. Reciprocally, criminal theories may also have "important ways of shedding light on" this debate (Farrington, Snyder \& Finnegan, 1998:462). For example, "if there is only one underlying theoretical construct, then offending would be versatile rather than specialized". Also, prediction of the future crimes types would not be possible by knowing the types of previously committed crimes. On the other hand, "if different types of offending reflect different theoretical constructs, then offending would be specialized rather than versatile". In this case, criminals would focus on certain crimes types repeatedly, and previous offenses would be useful to predict upcoming crime types (Farrington et al., 1998:462). To understand the arguments of criminal theories, we will present opposing theoretical assumptions on specialization versus versatility dispute in this section.

Numerous criminologists argue that there is great deal of specialization in offending. They claim that a number of criminals tend to specialize in violent crimes, while others specialize in property crimes; thus, they tend to commit the same types of crimes (Paternoster et al., 1998). Cohen defines this tendency as "offense clustering". Thus, specialization gives more likelihood of committing the crimes which are within the same cluster, such as property, violent, and status offenses (Lattimore et al., 1994).

\subsection{Proponents of Specialization}

A great number of the differential association, learning, subculture, and strain theorists support the notion of specialization. For example, Cloward \& Ohlin, and Sutherland support "specialization in crime" by arguing that juveniles learn crimes from other delinquents (Jennings et al., 2014:185; Tumminello et al., 2013:2). Cloward \& Ohlin clarifies the process of learning via detailing the interactions of juveniles with other delinquent peers. They claim that criminals specialize in either one of three different groups of offences: "criminal subculture (income related crimes), conflict subculture (violent related crimes), and retreatist subculture (drug abuse)" (2003:191-196).

Supporting Cloward \& Ohlin's thesis, Sutherland \& Cressey (2003) claim that individuals were not born with criminal behaviors, rather these behaviors are learned later in life through interaction with other offenders. Tumminello et al. argue that "Sutherland's theory support specialization in crime" because individuals copycat others' crimes and continue committing same crimes (2013:2). Additionally, Sykes and Matza argue that while delinquents know that "their delinquent acts are bad", they utilize "certain techniques of neutralization" such as "denial of 
Eker, A., \& Mus, E. (2016). Specialization in offending: A comprehensive review of criminological theories and empirical studies. International Journal of Human Sciences, 13(1), 2295-2322. doi:10.14687/ijhs.v13i1.3760

injury" and "denial of victim". More importantly, juveniles "learn these neutralization techniques" from their criminal environment and "becomes delinquents" (2003: 135-139). Since juveniles need justification for their certain acts, we can infer to some extent from this theory that they do not commit all the types of crimes. However, they focus only on certain types of crimes or "cluster of crimes" because they need to develop justification for crimes. In addition, developing "neutralization techniques" for different types of crimes, at the same time, would be very difficult. This includes justification of property and violent crimes simultaneously.

Biological theorists also claim that even though "biological factors do not directly cause crime or there is not a gene that leads directly to crime" (Cullen \& Agnew, 2003:27), biological deficits cause certain types of crimes. For example, serotonin regulates the "biochemical chain reaction" of the brain, while Rowe claims that low level of serotonin "is associated with violence" (2003: 67). Agnew states that low level of serotonin reduces individuals' "inhibition" capacity and cause "impulsive behaviors, aggressiveness, and irritability" (2005: 140-141). Thus, biological theories imply that individuals who suffer from the above mentioned "biological deficits" tend to commit violent crimes.

Likewise, Colvin and Pauly claim in their "Integrated Structural-Marxist Theory of Delinquency" that each "modern capitalist" society has different classes of people. Each class experience different "structures of control" imposed by "work, families, schools, and peer groups". The type of the control shapes the "ideological bonds" and behaviors of the individuals. For example, parents who are categorized as "working-class, blue-collar and white-collar occupants" face different level of coercive control at work. Furthermore, the level of coercive control they are subjected to shape their parenting style. As a result of control type, Colvin and Pauly claim that juveniles who experience high level of coercive control will commit more violent crimes (1983: 513, 533-542). Moreover, criminal will specialize in committing certain crime types, and "the type of specialization" will be a "function of their socioeconomic class". Additionally, "the same factors shaping the initial offense continually shape the subsequent offending pattern...within the larger context of social class in a capitalist society (Guerette et al., 2005:78).

\subsection{Opponents of Specialization}

On the other hand, Hirschi and Gottfredson clearly refuse the "notion of specialization" and claim that "offenders infrequently specialize" in crime because there is a great deal of versatility in committing crime (Richards et al., 2014:646). According to this assumption, low self-control is the main cause of crime. Therefore, people with low self-control will engage in wide variety of criminal acts (Paternoster et al., 1998). Gottfredson and Hirschi claim that "people who lack selfcontrol will tend to be impulsive, insensitive, physical (as opposed to mental), risk-taking, short sighted, and nonverbal; and they will tend therefore to engage in criminal and analogues acts". Hence, they claim that since offenders tend to commit "simple and easy" crimes that provide "immediate benefits", individuals with low self-control will take advantage of all criminal opportunities. For example, "obvious opportunities for an easy" crime such as "purse snatching" will be committed more frequently than other crimes. However, committing these crimes for several times do not cause specialization according to them. Consequently, they claim that although "some offenders may be called "robbers" or "rapists".....such labels are retrospective rather than predictive". Thus, these criminals commit several other types of crimes which are "inconsistent with their alleged speciality". Moreover, they point out an important problem of crime data by claiming that researchers tend to "focus on most serious crimes in series of events" and officials record, mostly the most serious crimes. Thus, Gottfredson and Hirschi assert that proponents of specialization in crime ignore several least serious crimes committed by the same person, and conclude that there is "great variability in the kinds of criminal acts" (2003: 244-247).

Cornish and Clarke, leading influential rational choice theorists, argue that criminals commit different crimes for different reasons and for different needs. Hence, offenders "decide to commit a particular offense" to fulfill their needs, such as money. Therefore, to prevent crime, "rational 
Eker, A., \& Mus, E. (2016). Specialization in offending: A comprehensive review of criminological theories and empirical studies. International Journal of Human Sciences, 13(1), 2295-2322. doi:10.14687/ijhs.v13i1.3760

choice theorists argue that "crime-specific" models must be employed" (Cullen \& Agnew, 2003:278). However, they warn students of criminology that the term "crime-specific" "is often misleadingly seen to entail some degree of crime specialization on the part of the offender. This, however, is to mistake the function of such decision models: to say that the models are offencespecific is not to say that the offenders in question commit only these offences" (Cornish \& Clarke, 1989:105). Moreover, although rational choice theory proposes that "offenders chose to commit particular crimes to meet their respective needs", they do not specialize in those types of crimes (Guerette et al., 2005: 80).

Furthermore, contrary to the argument mentioned above, Mazerolle et al. argue that "other criminological theories, like general strain, social learning, and labeling theories, harmonize with the expectation that offenders are not likely to specialize in particular types of crime" (2000: 11451146). Thomas (2016) clarifies this argument by claiming that differential association with others and learning from them increases the opportunities and knowledge of different crimes. Thus, these theories anticipate versatility, and not specialization in offending.

Additionally, developmental theorists claim that causal factors to onset crime, persistence, level of seriousness, or desistence from committing crime are subject to change throughout the life span (Piquero, 2000). Although their assumption anticipates different causes for committing crime, and seems opposite of Hirschi and Gottfredson's one causal model for all types of crime, they share the same assumption with them about specialization and claim that criminals commit different types of crimes throughout their life course (Piquero, 2000).

\subsection{The Middle Ground}

However, the above explanations should not be misunderstood as developmental theorists support versatility. In fact, rather than supporting either one of these two distinct anticipations, developmental theorists "occupy the middle ground between theories that emphasize offense specialization and those that implicate greater versatility in offending" and make complex assumptions in the degrees of specialization of different offender subgroups (Mazerolle et al., 2000, 1146). For example, Moffitt (1993) classifies offenders as "adolescence-limited offenders described as primarily committing nonviolent crimes" and "life-course persistent offenders" who "commit a range of crimes" as they get older throughout their long criminal career (Richards et al., 2014:646). Moffitt and Patterson claim that late starter and adolescent-limited juveniles are more likely to specialize in a few possible offenses. However, these criminals commit certain types of crimes which "symbolize adult privilege or demonstrate autonomy from parental control, such as vandalism, substance abuse, running away, and theft" (Paternoster et al., 1998:134). Contrary to adolescence-limited offenders, early starter/ life course-persistent criminals are more likely to commit wide variety of all available crimes as they get older throughout their long criminal career (Paternoster et al., 1998 and Richards et al., 2014).

In contrast to Moffitt and Patterson's claim, McGloin et al. argue that when offenders get older, they enter into the "desistance process, sparked by turning points"; and the process "involves both a decline in the frequency of offending and a narrowing of the criminal repertoire with regard to crime types (2011:362). As it is seen above, "criminologists who adhere to a developmental perspective" claim that offenders' behaviors are not that simple because they are affected by different variables throughout their life; thus, they present "a combination of specialized and generalized criminal behaviors" (Richards et al., 2014: 646).

Similar assumptions are made by McGloin et al. that the level of specialization and versatility changes over time. For example, they claim that if there is "within-individual variation in offending frequency, there is also a within-individual variation in offending specialization. Furthermore, just as there is a systematic tendency for offending frequency to decline over the life course, so too does offending versatility. Thus, there is reason to suspect that the desistance process, sparked by turning points, may involve both a decline in the frequency of offending and a narrowing of the criminal repertoire with regard to crime types" (McGloin et al., 2011: 362). For 
Eker, A., \& Mus, E. (2016). Specialization in offending: A comprehensive review of criminological theories and empirical studies. International Journal of Human Sciences, 13(1), 2295-2322. doi:10.14687/ijhs.v13i1.3760

example, by examining "4000 Dutch offenders", they found that offenders reduce their crime range when they get married (2011: 371).

Much of the researches in developmental criminology and life-course theory are very important to understand and to shed light on specialization/versatility debate. This is because these researches were empirical and longitudinal, and were meant to examine both the predictors of offending (onset, persistence, and desistance) and the pathways of events that directed people into and out of crime (Farrington, 2003). The emergence of the notion of criminal careers which introduces the notion that offenders have careers much like people who has a legal job, also played a role in focusing attention on the life-course feature of crime (Blumstein et al., 1986; Piquero, Farrington \& Blumstein, 2003). Farrington (2003) states that the developmental and life-course crime theories examine three major issues; the development of offending and antisocial behavior, divergent risk factors at various ages, and the effects of life events. Thus, life-course crime theories are particularly concerned with analyzing individual changes in "offending" throughout life.

Blumstein et al. (1986) also argue that life course crime theories can also be seen as a further elaboration of the criminal career paradigm which became very famous in the 1980s by adding risk factors and life events. Piquero et al. (2003) similarly assert that developmental life- course theories constituted a response to criminal career paradigm. This is because this paradigm shifting enhanced the knowledge of criminal career findings, such as onset, continuation, and desistance. Yet, it paid only minimal attention to risk factors and life events. Moreover, life-course and developmental theorists try to explain the "within-individual developments in crime over time", and they focus on "the causal factors influencing development" of the individuals because these casual factors "may shift as the individual progresses along his or her behavioral pathway" (Bushway, Sweeten, \& Nieuwbeerta, 2009:260).

The life-course perspective was enhanced by the recognition that there is continuity or stability in antisocial conduct from childhood into adolescence and adulthood. On the other hand, scholars observed that the behavior of offenders can change or experience discontinuity (Mus \& Eker, 2011). Thus, the key theoretical issue in life-course criminology is explaining both continuity and change in offending. Therefore, the life-course theories can be divided into three categories. Firstly, there are those theories that argue that there is only continuity in offending (Gottfredson \& Hirschi, 1990). Secondly, there are theories stating that offending is marked by either continuity or change (Thornberry, 1987; Moffitt, 1993). Thirdly, there are theories contending that offending is marked by continuity and change (Sampson \& Laub, 1993).

In sum, theories support specialization because they hypothesize that personal traits, learning and association process, and the presence of several underlying reasons for crime involvement lead individuals to commit specific crimes. On the other hand, other theories that accept only one underlying factor for crime causation support versatility. Life-course and developmental theorists take a middle position and claim that "adolescent-limited offenders should exhibit far less versatility in their offending" and specialize in certain crimes that "allow them to demonstrate their independence from adult authority"; however, "life-course-persistent offenders will exhibit great versatility in their offending behavior (Mazerolle et al., 2000, 1146).

\section{Empirical Studies}

The dispute on crime specialization or versatility have been one of the major concerns of practitioners, and for "both crime scholars and public policy specialists" for several decades in terms of increasing the effects of "crime control efforts" and treatment programs (Mazerolle et al., 2000:1144). Therefore, numerous empirical researches had been carried out regarding this issue. Their results will be presented in this section.

In order to find out the answer to specialization problem, Farrington et al. made a research by using official data of nearly 70,000 juvenile offenders. That study showed that there are several underlying causes of crime which support the specialization in offending (1988). Almost $20 \%$ of the delinquents were found as specialists regardless of their genders and ages. "Runaway, liquor, 
Eker, A., \& Mus, E. (2016). Specialization in offending: A comprehensive review of criminological theories and empirical studies. International Journal of Human Sciences, 13(1), 2295-2322. doi:10.14687/ijhs.v13i1.3760

incorrigibility, burglary, motor vehicle theft, and drugs" were often regarded as the most specialized offenses. Also, "vandalism, possessing stolen property, delinquent traffic, and trespassing" were found as the least specialized offenses. They also found that "specialization tends to increase with successive referrals, especially for the persistent offenders with 10 or more referrals. Hence, it was concluded that the observed increase in specialization was not due to attrition" (Farrington et al., 1988:483).

To find out whether specialization in offending exists, other researchers examined the offenders' characteristics which were assumed to be important in affecting the crime type. For example, Armstrong and Britt claim that if any type of crime is attractive to an offender because of personality characteristics, same type of offenses might be committed to 'satisfy recurring personality needs" which are caused by "stable personality traits throughout life course" (2004:847). Their study showed that some types of offenses are more attractive to some offenders, while other crimes are less. They stated that knowing "individual background characteristics" are very useful to make any prediction of "criminal behavior generally", and "characteristics of individuals that predict any criminal behavior also predict different type of criminal behavior" (2004: 868).

Lattimore et al. (1994) stated that parolees are more likely to be rearrested for the same type of offense for which they were imprisoned when Bureau of Justice Statistics were examined by researchers. For example, it is found that "parolees were often rearrested for the same crime type for which they were incarcerated. This pattern was especially evident for robbery, fraud, assault, and drug offenses. Also, property offenders with prior arrest for a violent offense were rearrested more often for a violent offense (43\%) than those without prior violent arrests (29\%)" (Lattimore et al., 1994:294). The researchers also made a study by using 2000 males who were released from the California Youth Authority, and found evidence of specialization. Due to their study results, the knowledge of current and the preceding offenses can be used to predict the next offense type. Criminals who committed the same type of two successive offenses are more likely to commit the same type of offense at the third time than any other type of crime (Lattimore et al., 1994). In addition, Cohen says that specialization in offending "emerge gradually as offending continues over time, largely through a learning or experiential process. They repeat what they do well, and desist what they do poorly, or with too costly benefits" (Piquero et al. 1999:295).

McGloin, Sullivan \& Piquero (2009) found exactly opposite results by examining 658 criminal males. Thus, they claim that criminals commit same types of crimes for short term because of the available opportunities for that certain crime types. This research found that "because of changing situations and contexts over the life-course, their offending profiles aggregate to versatility over the criminal career" (2009: 243). Likewise, Klein (1984) found that juveniles tend to commit "cafeteria-style delinquency" (versatility in committing crimes) by reviewing thirty-three studies: 21 of the studies support versatility, eight of them show mixed results, and only four of them have evidence of specialization. Contrary to Farrington et al. claim, Klein found in the Heuser's study that if the numbers of subsequent offenses increase, the versatility will increase, and not the specialization. The reviewed studies showed that there was a general underlying cause of crime for delinquency, and not different factors for each type of crime. Therefore, juveniles commit wide variety of offenses (Klein, 1984).

Alternatively, as mentioned above, Kempf criticizes both assumptions which accept or reject specialization in offending. He argues that results should be evaluated carefully because problems which affect the findings of the studies exist "in the areas of crime category specification, portion of career examined, and method of measurement (1987:403). He claims that rejection or acceptation of specialization is "premature" because studies have been misled by the inaccurate measurement methods (Kempf, 1987). He suggests that crime categories should be "mutually exclusive", and longitudinal studies should be done.

Although empirical studies present controversial results on specialization, legislators and practitioners doubtlessly believe that certain criminals specialize in offending (Mazerolle et al., 2000). Therefore, following parts of this paper will present the results of the empirical studies that 
Eker, A., \& Mus, E. (2016). Specialization in offending: A comprehensive review of criminological theories and empirical studies. International Journal of Human Sciences, 13(1), 2295-2322. doi:10.14687/ijhs.v13i1.3760

analyzed the effects of age, gender, and peers on crime specialization. Furthermore, we will try to explain the process through which these variables form the nature of offending. Later, the results regarding whether offenders specialize in violent, nonviolent and sex crimes will be presented.

\section{1. $\quad$ Age Effect}

Several criminologists have dedicated most of their interests on teenage years and delinquency. Therefore, the majority of the empirical tests of numerous criminological theories have been conducted on adolescent delinquency for decades. The reason for this is related with the age-crime curve which suggests that the peak age for offending is mid-teenage years and most of the crimes are committed by juveniles. Thus, in criminological analysis, teenage stage in the life course is known to generate high rates of illegal behavior (Moffitt, 1993; Sampson \& Laub, 1993). For example, Caspi \& Moffitt (1995) noted that the delinquency curve reaches its highest point at approximately 17 years of age. In addition, they found that most of the crimes are committed by teenagers and when they reach their 20s, almost half of the "active offenders" stop committing crime, and nearly 85 percent of the delinquents discontinue in committing crimes when they reach age 28 .

Relationship between age of onset and specialization is very important because offenders who start to commit crime at their early ages are more likely to commit high frequency of crimes over a long period of time (Piquero et al., 1999). If specialization exists, it will be possible to predict the later offenses by knowing first crimes at early ages. Therefore, designing tailor-made effective intervention techniques and criminal justice policies would be possible (Piquero et al., 1999).

Hirschi and Gottfredson claim that "individuals with low levels of self-control will be more likely to begin offending early in life, offend more frequently while active, and desist later in life" (Piquero et al., 1999:279). They also say that self-control is directly related to diversity of crimes. Therefore, offenders who start committing crime due to low self-control tend to commit more different types of crimes throughout their lengthy criminal career (Piquero et al., 1999).

Moffitt suggests that youth who are not socialized enough are more likely to engage in criminal activities at their early ages, and "inadequate socialization is positively related to offense versatility" (1993:282). Therefore, early onset and offense versatility has a strong relation (Piquero et al., 1999). Moffitt also claim that while "life-course persisters" have tendency on versatility, "adolescent-limited offenders" who "initiate offending at a later developmental age (not until midadolescence)" are "more specialized than the life-course-persistent offender" (Mazerolle et al., 2000:1147). Moffitt clarifies the reasons why "adolescence-limited offenders" have tendency on specialization. Thus, she claim that they "engage primarily in crimes that symbolize adult privilege or that demonstrate autonomy from parental control: vandalism, public order offenses, substance abuse, and "status" crimes such as running away and theft" (1993:695). On the other hand, "lifecourse-persistent offenders" have versatility in crime because these juveniles face "neuropsychological problems, criminogenic home environments, discipline problems, and academic failures". This is especially since their childhood and cumulative effects of these "maladaptive individual dispositions" prevent their "recovery", and "delinquents are channeled into antisocial adult life-styles as time passes" (1993: 694-695). Moreover, she also claims that "lifecourse-persistent antisocial behavior is a form of psychopathology" (1993: 679). Thus, we can infer from Moffitt's findings that this group of criminals take advantage of all crime options and commit different types of crimes.

Similarly, Mazerolle et al. carried out a study to evaluate the above mentioned arguments by using "1958 Philadelphia Birth Cohort". They only "included 3,655 individuals who had two or more official police contacts for criminal activity". Females composed of 13 percent of the sample. Their results were in consonant with the claims of Moffitt, Hirschi, and Gottfredson which states that "offenders who begin their offending behavior early in the life course and persist into 
Eker, A., \& Mus, E. (2016). Specialization in offending: A comprehensive review of criminological theories and empirical studies. International Journal of Human Sciences, 13(1), 2295-2322. doi:10.14687/ijhs.v13i1.3760

adulthood, exhibit more diverse and versatile offending patterns than those who do not" (2000:1152).

Although most of the above mentioned researches suggest that early onset age causes versatility, Armstrong and Britt made an opposite prediction. They claim that youths who grow up in a family environment where they have chance to observe their criminal parents 'or siblings' offenses are more likely to specialize in certain offenses. They have opportunities to learn committing certain crimes successfully, and start at their earlier ages to commit those crimes. Therefore, they specialize in certain types of crimes (2004).

On the other hand, Piquero et al. (1999) look at an interesting point. They claim that the predicted onset age effect might actually be the effect of age itself. Stating this in a different way, older criminals tend to commit same type of crimes regardless of their onset ages. They studied 3,655 individuals from the 1958 Philadelphia Birth Cohort. However, they found that there is no significant relation between onset age and versatility. They claim that age effects decrease versatility (Piquero et al., 1999). Nagin and Paternoster also support this view and claim that with age, offenders gain other capitals, and start to make rational choices. If they still want to engage in criminal activities, they select low risk crimes with high benefits; thus, this tendency increases their degrees of specialization (Piquero et al., 1999). Loeber and LeBlanc also suggest the similar behavioral patterns of older offenders. By age, behaviors are more likely to become organized and interdependent. Therefore, offenders narrow their offense types to low risk and high gain crimes (Piquero et al., 1999).

Similarly, Nieuwbeerta et al. examined a large sample of "Dutch offenders through age 72 $(\mathrm{N}=4,615)$ ". Thus, they found that offenders tend to commit very different types of crimes throughout their life span and conclude that "there was diversification-increasing diversitybetween early adolescence and young adulthood, and then specialization-declining diversityduring adulthood" (2010:19). Furthermore, Blumstein et al. found similar results by observing criminal records of " 32,197 adults (age 17 or older) from Detroit". They concluded that older criminals present more specialization in offending than younger delinquents. Moreover, they found that "adult offending becomes more specialized and escalates in seriousness" (1988: 303, 308).

Tumminello et al. examined the levels of "specialization across ages". They found two important results. First, the levels of specialization increases as the ages of offenders increase. Older criminals reduce their versatility and commit only specific "types of crimes belonging to a single cluster". Tumminello et al. give three explanations for this outcome: "suspects tend to specialize over time"; presence of "a group of specialized individuals who remain in crime; and a cohort effect such that the younger generation tends to consist of generalists while the older generation consists of specialists" (2013: 6-7). Secondly, they revealed that offenders specialize in certain types of crimes "temporally". In other words, different age groups commit significantly high levels of certain crime types. For example, young offenders preferentially commit "drugs/weapons, vandalism/graffiti, mugging, and murder", whereas older offenders excessively commit "arson" (2013: 7-8).

Researchers also examined the abuse of illegal drugs and age relationships. For example, Hawkins, Catalano \& Miller claim that the use of alcohol or other drugs at an early age is an indicator of future alcohol or drug problem. Youth who use these substances increase their lifetime dependency chances. People who begin drinking before age 15 are four times more likely to develop alcoholism than those who begin at 21 (1992: 78). Anthony and Petronis support this idea and claim that people who started drug use earlier (under age 15) will have higher lifetime prevalence of drug abuse problems than the drug users who started in mid-adolescence (between 15 and 17 years of age). Also, youth who delay substance use until age 21 almost never develop substance abuse problems (1995:10).

Finally, Gfroerer et al. argue that youth who started abusing themselves with the use of marijuana before the age of 15 were found to have a higher ratio of cigarette use than those adolescents who started at age 15 or older. "Early-onset marijuana users were also much more likely 
Eker, A., \& Mus, E. (2016). Specialization in offending: A comprehensive review of criminological theories and empirical studies. International Journal of Human Sciences, 13(1), 2295-2322. doi:10.14687/ijhs.v13i1.3760

than other initiates to have begun using marijuana prior to any use of cigarettes or alcohol". Additionally, "adult onset marijuana users reported a higher proportion of prior use of alcohol." (2002: 47).

\subsection{Gender Effect}

Chesney-Lind and Faith claim that criminology is dominated by males, and as a reflection of this overrepresentation, "women's crime was overlooked almost completely and female victimization was ignored, minimized, and trivialized" (2001: 287). Same patterns are present in crime specialization studies. This is because although there are huge amount of researches on crime specialization, far fewer studies have analyzed gender effect on crime specialization. One of the important reasons for this low focus on gender differences is caused by the belief that most of the serious and violent crimes are committed by males. Other reason comes from Moffitt's theory that "males are expected to have greater representation in the life-course persister category relative to females, while female participation in adolescent-limited offending patterns is expected to be substantial" (Mazerolle et al., 2000: 1149). Moreover, following the arguments of routine activities theories, Osgood et al. claim that females engage in "unstructured socializing activities much less often than males" (1996: 649). Becker and McCorkel also examined more than 20 million offenders" crimes by using NIBRS data set. They found that " $62.49 \%$ of the offenders were male", and only " $19.90 \%$ were females". Moreover, most of the serious crimes such as "homicide, rape and forcible sex offenses, robbery, kidnapping, arson, burglary, theft from a coin-operated machine or device, theft from a motor vehicle, theft of motor vehicle parts, weapons law violations, stolen property offenses, drug sales, and gambling offenses" are committed by males; whereas women only constitutes the "largest proportion of embezzlement and prostitution". Furthermore, they argue that the gender of an individual has dominating effect on limiting and "shaping both social location and social relationships", and these limited "social networks" reduce the availability of "illicit opportunities" (2011: 7, 10, 24). Thus, females are seen to be less dangerous when compared to males. Thus, researchers focused more on male behaviors. However, as Moffitt claims in the above quoted sentence, females also commit "substantial" amount of crimes. Becker \& McCorkel (2011) also discovered that 19.9 percent of 20 million criminals (almost 4 million) are female offenders. Moreover, Mazerolle et al. claim that "while male dominance is expected, female representation in the life-course-persistent group may nevertheless still occur" (2000: 1149).

In addition, the presence of important amount of female offenders, whether males and females, that differs in offense specialization has been the major concern of researchers. Since girls and boys are very different in terms of biology and interests, subject to different levels of "direct control, such as surveillance and supervision" by their parents, and girls are "socialized toward greater conformity and less risk-taking than males", females are expected to commit certain types of crimes (Vold, Bernard \& Snipes, 2002: 276). Therefore, whether females and males differ in offending styles has important policy implications to reduce crime. The findings of empirical studies will be mentioned below.

Farrington, Snyder and Finnegan examined crime patterns of " 28,201 juveniles with two or more referrals". They found that $80 \%$ of the sample juveniles were found as versatile, while only $20 \%$ of them were "identified as specialists". Their results revealed that females are more "likely to be specialists" than males, especially "in runaway offenses, fraud or forgery, disorderly conduct, and liquor". This study found that "females with 10 or more referrals were significantly more likely to specialize than the males ( $47.1 \%$ of 136 females were specialists, in comparison with $16.8 \%$ of 1,843 males)". Subsequently, both males and females' "least specialized offenses were vandalism, possessing stolen property, delinquent traffic, and trespassing". Interestingly, this study did not find that females specialize in shoplifting; although, it is generally believed that girls commit more shoplifting offenses (1998: 478, 483).

Tumminello et al. examined crimes of 336,000 females and males in Sweden, and found that females generally commit fewer clusters of offenses, while males tend to commit more clusters 
Eker, A., \& Mus, E. (2016). Specialization in offending: A comprehensive review of criminological theories and empirical studies. International Journal of Human Sciences, 13(1), 2295-2322. doi:10.14687/ijhs.v13i1.3760

of crimes. Moreover, they found that females have more tendency than males toward specialization. For example, $34 \%$ of the females and $27 \%$ of the males were found as specialists "with respect to the pure generalist cases" (2013:6).

Osgood and Schreck gathered information from three data sources (Monitoring the Future, Montreal Study and G.R.E.A.T, pg. 288-290) to examine offence specialization of males and females. They claim that they "obtained clear evidence of specialization" due to excessively large data sets. According to statistically significant results of this study, males "specialize in violence" more than females (2007: 299). On the other hand, Bouffard et al. found opposite results when they examined incarcerated female offenders' violence. Their research revealed that imprisoned males are less likely to specialize in "intimate partner violence" since they commit different types of offends. "Interestingly, it is female "perpetrators" who are more likely to specialize" in violence (2008: 590).

Kempf also examined whether males and females differ in offense specialization by examining the personal information "1958 Philadelphia Birth Cohort data of 27,160 males and females (13,160 males and 14,000 females)". Thus, the results of the study "showed a low level of specialization amid more random, general, or versatile behavior" of both males and females (1987: 405, 416). Mazerolle et al. criticize this study and claim that although this study found that females specialize more than males in "status offenses, this study is limited because there are no formal tests and is based instead on "eyeball" comparisons across gender groups on offense transitions" (2000: 1150).

On the contrary, Mazerolle et al. found opposite results. They examined the effects of gender and age onset of crime specialization by using 3,655 criminals' individual-level information. $13 \%$ of the sample was females. They found that there was no significant difference between males and females in terms of crime specialization. Results of this research revealed the "relationships among onset age, persistence, and offending specialization that were largely invariant and perhaps even more pronounced for female offenders". These results contradict the findings of empirical studies that females commit less violent crimes. Mazerolle et al. claimed that most of the studies fail to capture the "female diversity" because females shift their crimes "between the property and other adult status offenses" (2000: 1152,1167).

Rojek and Ericson analyzed almost 1200 males and females who were sent to juvenile court. They used "official records rather than self-report data" by claiming that official data is more useful to capture the "sequencing of offenses". They found that even though juveniles' crime number goes up, they do not commit only one cluster of crimes. Instead, they commit all types of crimes. Moreover, they found that "there was no evidence that male or female juveniles specialize in a particular type of offense as their official career develops, although the nature of their involvement differs". However, they only found a slight evidence of specialization for females in runaway deviant behavior (1982: 26). Hindelang used self-report data rather than using official records. They composed of the information of "763 high school students (319 males and 444 females)". Similar to the result of Rojek and Ericson study, he found that neither males nor females specialize in offending. Moreover, contrary to the general assumptions, he found that females display more tendencies toward versatility than male criminals (1971: 523).

\subsection{Peer Effect}

Criminologists generally accepted that many empirical researches found ample evidence that spending more time with other peers "in unstructured socializing activities" increase the chance of being in "situations conducive to deviance". However, these situations give juveniles abundant opportunities to "engage in deviant behavior more frequently in the company of others" (Osgood et al., 1996: 639). Researchers also explain the process of how and why hanging out with peers promote chance of committing crimes by claiming that "the lack of structure leaves time available for deviance; the presence of peers makes it easier to participate in deviant acts and makes 
Eker, A., \& Mus, E. (2016). Specialization in offending: A comprehensive review of criminological theories and empirical studies. International Journal of Human Sciences, 13(1), 2295-2322. doi:10.14687/ijhs.v13i1.3760

them more rewarding; and the absence of authority figures reduces the potential for social control responses to deviance" (1996: 651).

However, although criminologists generally accept that spending more time with other peers promote chance of engaging in criminals acts, several criminologists try to explain whether peer-effect causes specialization or versatility. Some researchers claim that peers produce different opportunities for crime involvement in terms of "frequency and crime types". As a result, individuals commit very diverse crimes. Opponents of this view claim that effect of criminal peers cause specialization because peers learn from each other (Thomas, 2016; Tumminello et al., 2013). Finding out the answer to this question may have important policy implications in terms of "providing insight on the role that friends play in promoting versatile" or specialized in offending, and discovering whether "changes in one's peer group is associated with changes in offense types" (Thomas, 2016:31). Furthermore, the results of the studies carried out by both opponents and proponents will be presented below.

Thomas asserts from previous studies that "associating with peers should produce not just a difference in offending volume, but a difference in offending type(s)". Thus, he claims that "there are theoretical and empirical reasons to believe that peers can promote diversity in offending". "From a learning perspective", juveniles learn committing different crime types from other delinquents, and "from an opportunity perspective". By spending much of their time with other peers outside their homes "increase the types of criminal opportunities available for potential offenders" (2016:27). Thomas carried out a study to test the above arguments by examining offense patterns of 1554 individuals who had more than two police contacts to find out whether "delinquents who are isolated from peers are more likely to specialize in their offending, or if they display similar levels of versatility as those who associate with friends" (2016:44). This study revealed that lonely delinquents specialize in crime, while nonisolate offenders commit different types of crimes. Moreover, Thomas also found that lonely individuals shift from being specialized to versatility in offending when they change their social status and start to spent time with other delinquents. These results improve our knowledge on the manners of lonely delinquents that "their offending nature differs from adolescents who are members of friendship groups" (2016: 44).

Thomas also mentions Sutherland's claim (1947) that "normative peer influence shapes the amount, as well as the character of offending.... because individuals are responsive to the normative definitions that they provide for engaging in delinquent behavior". Individuals can learn those definitions and offenses via peer associations which provide "a greater range of antisocial behaviors which, in turn, leads them to display greater versatility in delinquency" (2016: 30). Contrary to Thomas' argument, Tumminello et al. discuss that Sutherland's differential association theory validates the notion of specialization because "the theory assumes that the individual's behavior is influenced by the total outcome of the influences received from the social environment" and the crime itself; and the method of committing that specific crime is learned from others (2013: 1).

Supporting the arguments of Tumminello et al., Warr found that peer groups cause specialization through examining group delinquency by using National Surveys of Youth data obtained through "in personal interviews with national probability sample of 847 adolescents aged 13 to 16" (1996: 19-20). He found that delinquent groups have tendency of specialization in crimes because these groups are generally composed of individuals who have the desire and ability to commit certain crime types. Moreover, Warr argues that since "groups tend to specialize in forms of delinquency, then offenders must belong to different groups in order to engage in different forms of delinquency (e.g., auto theft, shoplifting, robbery)" (1996:26). We can infer from his findings that "instigators" can be the reason for criminal groups specialization in certain crime types because each delinquent groups generally has an instigator who is "mostly older, male, and has closeness" with group members, and are "more experienced in crime" (1996: 26-30). Thus, since they have natural power to affect other peers, group members follow these instigators in certain crimes. 
Eker, A., \& Mus, E. (2016). Specialization in offending: A comprehensive review of criminological theories and empirical studies. International Journal of Human Sciences, 13(1), 2295-2322. doi:10.14687/ijhs.v13i1.3760

Similarly, Cloward \& Ohlin, and Sutherland, support the notion of "offense clustering". Therefore, they claim that "lack of legitimate opportunities" and "learning process through interactions with" other delinquents lead to "specialization in crime" (Jennings et al., 2014:185; Tumminello et al., 2013:2). For example, Cloward \& Ohlin claim that "availability of illegitimate means" and "social structures" through which delinquents "must establish relationships with other categories of persons, all contribute in one way or another to the successful performance of criminal activity". In the course of this process, delinquents specialize in three types of criminal activities: "criminal subculture - a type of gang which is devoted to theft, extortion, and other illegal means of securing income; conflict subculture - a type of gang in which the manipulation of violence predominates as a way of winning status; and retreatist subculture - a type of gang in which the consumption of drug is stressed" (2003:191-196).

Sutherland and Cressey also claim that "criminal behavior is not inherited" and individuals learn committing crime from others. However, "when criminal behavior is learned, the learning includes: (a) techniques of committing the crime and (b) the specific directions of motives, drives, rationalizations, and attitudes" (2003:132). Since crime and the methods of committing that crime is learned from others, researchers claim that "Sutherland's theory on differential association support specialization in crime" (Tumminello et al., 2013:2).

McGloin \& Piquero (2010) supported the above theoretical claim with an empirical research. They analyzed offending patterns of randomly selected 218 delinquents who committed crimes with other peers to find out whether co-offending cause specialization or versatility. They found clear evidence of association "between the level of redundancy in a delinquent's cooffending network and offending versatility". Delinquents who commit crimes within dense "cooffending networks" specialize in committing certain crime types. On the contrary, juveniles who commit crimes within nonredundant networks (less dense linkages among group members) had a tendency to commit different types of crimes when they commit with other peers (2010: 77-78). McGloin and Piquero argue that less dense criminal networks "provide access to varied information, skills, and opportunities, which provide individuals with broader social options and experiences". However, redundant networks (dense linkages among group members) restrain skills of the group members, gaining access to different criminal opportunities, and experiences of other criminals (2010: 78).

\subsection{Violent vs. Nonviolent Crimes}

Crime categories are roughly classified into three basic groups: violent, nonviolent (property) offenses, and other crimes. Violent crimes include "hitting someone, attack with a weapon, homicide, aggravated assault, simple assault, robbery, gang fight, rape, and carrying a gun", and so on. Nonviolence crimes involves "burglary, theft, embezzlement, damage property," and etc. Other crimes are "drugs, prostitution, etc." Researchers defined "specialization in violence as the tendency for individuals to engage in violent rather than nonviolent offenses, independent from their overall rate of offending" (Osgood \& Schreck, 2007: 300, 310; Mozerolle et al., 2000: 11551156).

Whether criminals have a tendency of committing either violent or nonviolent crimes has been a challenging question for practitioners, policy makers, and academics. If offenders have an inclination to commit either type of crime, "then it may be possible to improve the justice system through practices such as selective detention and targeted treatment". Moreover, if specialization in violent or nonviolent crimes is present, crime theorists will be directed to clarify the underlying reasons for selecting either crime type (Osgood \& Schreck, 2007: 274).

Researches on whether offenders specialize on either violent or nonviolent crimes have found mix results. For example, some researchers found that offenders specialize in nonviolent crimes, such as theft, fraud, and burglary (Britt, 1996; Farrington, Snyder, \& Finnegan, 1988). On the other hand, researches that focused on the damage and malfunctions of the brain due to "genetic or nongenetic reasons, such as delivery complications, mother's alcohol and drug use, and 
Eker, A., \& Mus, E. (2016). Specialization in offending: A comprehensive review of criminological theories and empirical studies. International Journal of Human Sciences, 13(1), 2295-2322. doi:10.14687/ijhs.v13i1.3760

reduced levels of serotonin in the brain" claim that individuals who suffer from these malfunctions tend to have "low self-control" and "tend to be "impulsive, aggressive, and irritable" (Agnew, 2005: 140-141). Thus, these aggressive persons specialize in offending violent crimes (Tumminello et al., 2013: 1). In addition, other researchers found evidence of specialization for both violent and nonviolent crimes (Brennan, Mednick, \& John, 1989).

Tumminello et al. analyzed crime patterns of 336,000 offenders in Stockholm, Sweden. Their research found that offenders have tendency to commit different types of crimes, but "specialize in certain offenses". As shown in Figure 1, these minor clusters of offenses include "sexual molestation of children, sexual molestation, environmental crime, murder, robbery, drugs, weapons, vandalism, graffiti, and mugging" (2013: 2-8). Tumminello et al. "set a link between two clusters if at least one significant co-occurrence can be detected between a type of crime belonging to the first cluster and a type of crime belonging to the second one" (pg. 5). Therefore, this figure is an excellent illustration of crime types and clusters of offenses. Also, it guides researchers in understanding versatility, specialization, and linkages between clusters of offense types. In other words, "large group of suspects can be described as generalists", but there are "non-trivial pattern of specialization across the age and gender of suspects" (2013:1).

Figure 1. Interrelations of clusters of statistically validated network of types of crimes*

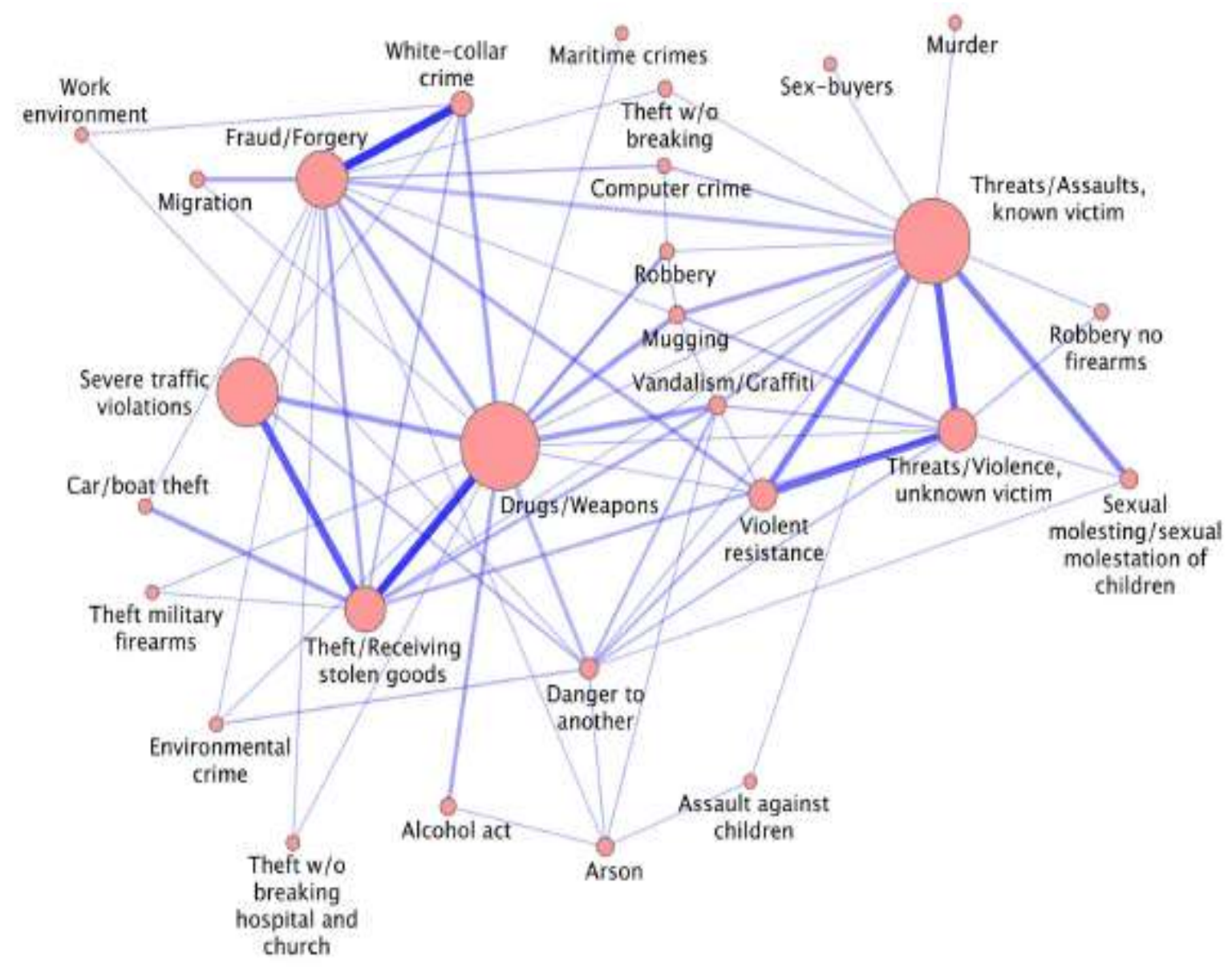

*Source: Tumminello et al. (2013: 6).

Moreover, Mazerolle et al. claim that offenders' specialization in either violent or nonviolent crimes will be determined by the characteristics of the neighborhood where they live and with the "class position" to which they belong. Basing their argument on "the differential opportunity theory of Cloward \& Ohlin (1960)", Mazerolle et al. state that based on the culture and 
Eker, A., \& Mus, E. (2016). Specialization in offending: A comprehensive review of criminological theories and empirical studies. International Journal of Human Sciences, 13(1), 2295-2322. doi:10.14687/ijhs.v13i1.3760

characteristics of the neighborhoods such as "conflict culture", occupants of those localities will "specialize in violent/predatory offenses while other types of neighborhoods will foster greater specialization in property offending or substance use". Additionally, by using the "work of Colvin \& Pauly (1983) who argue class position", Mazerolle et al. claim that individuals who live in different structural levels of society experience different kinds of control. For example, "lower class workers experience more coercive kinds of disciplinary controls than professional or white-collar workers, who experience more instrumental and normative controls". Thus, class positions and types of control exposed to them determine the level of specialization "in violent as opposed to property offenses" (2000:1145).

Correspondingly, Youngs, Ioannou \& Eagles' research on 200 convicted criminals revealed similar results that unlike "instrumental crimes (monetary gains, etc.)" which requires onward planning and necessary skills, "expressive crimes" are caused by impulsiveness of the individuals. Therefore, those "expressive type of aggression occurs in response to anger-inducing conditions, resulting in an immediate interpersonal confrontation that is most likely to occur against someone that the victim knows intimately". Moreover, they conclude that offenders specialize in "expressive or instrumental" crimes and focus either on "person and property" (2014:18-20).

Similarly, Brennan, Mednick and John found that offenders specialize in property and violent crimes by examining 28,884 criminal men in Denmark. According to their results, "specialization for property offending seems most apparent for offenders with low numbers of arrests". Different from property crimes, offenders with prior three or more arrests for violent crimes tend to specialize in violent crimes. In addition, Brennan et al. claim that the more an offender commit violent crimes, the more level of specialization in this type of crime will be presented. Thus, prior violent crimes and "indicators of higher levels of recidivism" can be used as a tool for "predicting future violent offending" (1989: 449-451).

Osgood and Schreck carried out an ambitious study by using three different and enormous data sources to clarify the "stability of specialization over time" and association of specialization with "explanatory variables". Moreover, they tried to determine the "extent and statistical significance of specialization". Osgood and Schreck claim that by analyzing three different data sets, they found significant "evidence of specialization" in violent crimes on the contrary to previous studies. Furthermore, despite the fact that previous results, such as National Research Council report found association between specialization in violence and high level of crime engagement, this research demonstrated that even the criminals who offend infrequently specialize in violent crimes. Additionally, Osgood and Schreck reached an exceptionally valuable result that individual offender's propensity toward "specialization in violence" is "stable over time". They also claim that their "new technique to accommodate independent variables is highly useful to predict who will specialize" (2007: 274, 300-301).

Furthermore, Lynam, Piquero and Moffitt carried out a longitudinal study by following 980 youths from their early childhood (birth or age 3) until the age of 26 in New Zealand. They used both "self-report and official data". Results of this study show that official data did not determined specialization in crime, but self-report data presents evidence of specialization in violent crimes. They claim that early onset and "particular set of personality traits", such as "negative emotionality, suspicious, alienated, callous, cruel, unempathic, and prone to overreact to stress" lead to specialization in violent crimes (2004: 224-225).

Piquero also found similar results. He carried out a study in which he looked at family background (family structure, maternal education, pregnancy complications, SES, etc.), child development (low birth weight, neurological abnormalities, school disciplinary, etc.), criminal offending, and police contacts. He found that male offenders with low verbal IQ are more likely to commit violent offenses (Piquero, 2000:406, 408). His study also showed that when the frequency of committing crime increases, the probability of committing violent crime also increases (2000: 408). Moreover, Moffitt found that offenders who started to commit crime at their early age exhibit more aggressive behaviors, and commit more violent crimes (Piquero et al., 1999). 
Eker, A., \& Mus, E. (2016). Specialization in offending: A comprehensive review of criminological theories and empirical studies. International Journal of Human Sciences, 13(1), 2295-2322. doi:10.14687/ijhs.v13i1.3760

However, Nieuwbeerta et al. studied the crime types of 4,615 criminals' during childhood and adulthood years. They found that criminals have a tendency to "specialize in property crimes during adulthood". Their research revealed that criminals will focus more on property crimes while they get older (2010:19). It is a well-known fact that old people pay more attention to secure their life expenses. Thus, we can deduce from this research that older criminals specialize in property crimes to satisfy their economic needs.

Andresen and Linning analyzed the effect of unemployment and low-income on crime specialization by examining data from "10 Canadian provinces for the years 1981-2009, a total sample of 290 observations". As seen in Table 1, they found clear evidence of crime specialization caused by "unemployment, gross provincial product (GPP), GPP per capita and low-income". Thus, they claimed that these results were "statistically significant in multiple contexts, and are theoretically justified". For example, they found that low level of "gross provincial product (GPP)" decreases the level of specialization in violent crimes, but increases the level of specialization in only property crimes. On the other hand, they found that "gross provincial product per capita (GPP per capita) causes specialization in only violent crimes even though it is an economic factor. However, this research found mix effects for low income and unemployment. Since low income is the exact indicator of "economic hardship", offender who suffer from low income have high tendency to commit crimes for economic reasons. Thus, low income causes "an increase in the specialization of most property crime types", such as "burglary, shoplifting and theft from vehicle". On the other hand, they also found that low income increases the level of specialization in robbery. Additionally, this research found that unemployed people experience more "economic stresses" which cause "specialization in shoplifting". However, they also found that individuals who are unemployed experience more "social stress and use of alcohol" which cause "specialization of assault" (2015: 7, 14-16).

Table 1. Effects of economic factors on crime type

\begin{tabular}{lllll}
\hline & Unemployment & GPP & GPP-PC & Low income \\
\hline Assault & + & - & + & - \\
Robbery & - & & + & + \\
Burglary & - & + & & + \\
Shoplifting & + & + & - & + \\
Theft & - & + & - & \\
Theft from vehicle & & + & - & + \\
Theft of vehicle & - & + & - & \\
\hline
\end{tabular}

Source: Andresen \& Linning (2015: 14).

To discover the level of specialization or versatility, researchers also examined the effects of offenders ` characteristics on committing violent and nonviolent offenses. Farrington carried out a study by using data from Cambridge Study in Delinquent Development. He found that violent and nonviolent offenders have the same childhood, adolescent, and adult characteristics, and concluded that causal effects for both violent and nonviolent crimes are same (Piquero, 2000). Capaldi and Patterson also found similar results which indicate versatility in offending that childhood behaviors, and family background of violent and nonviolent offenders were almost same by using both official and self-report data (Piquero, 2000).

\subsection{Sex Crimes}

Researchers define specialization in sex crimes as "the presence of a sustained pattern of offending where sex offences are predominant" (Lussier et al., 2012: 1576). Based on this definition, it is 
Eker, A., \& Mus, E. (2016). Specialization in offending: A comprehensive review of criminological theories and empirical studies. International Journal of Human Sciences, 13(1), 2295-2322. doi:10.14687/ijhs.v13i1.3760

generally believed that sex offenders are different than other criminals because of their "psychopathy or mental disorder that, unless treated, increases their dangerousness" (Simon, 2000:276). Therefore, practitioners and policy-makers base their decisions on the hypothesis that young offenders who commit sex crimes will continue to commit same brutal crimes when they reach adulthood (Lussier et al., 2012). The perception about sex offenders is that they specialize in sex crimes because "they are motivated by some mental disorder, usually deviant sexual arousal". Therefore, "continuity hypothesis" stresses that the probability of recommitting another sex crime by these offenders is more likely than any other criminals. Supporters of these assumptions base their claims on offenders' personality traits and "underlying motivation of the sex offences" (Simon, 2000: 279; Lussier et al., 2012: 1560).

Consequently, the hypothesis that "sex offenders are sex crime specialists" (Lussier \& Cale, 2013: 452) has tremendous effect on both legal and mental health policies, such as "registration of sex offenders, community notification, and commitment to mental hospitals after their prison terms, and more lax rules of evidence in sex offense cases" (Simon, 2000: 277-279). For example, previous sex offenses can be used as evidence of sexual propensity according to the Federal Rules of Evidence. By enacting these rules, Congress believes that sex offenders are mentally disordered, and they specialize in sex crimes. Police also base their sex offense investigations on these assumptions, and mostly look for the registered sex offenders to solve new sex offense cases (Simon, 2000:278).

On the other hand, "discontinuity hypothesis" claims that vast majority of the "juvenile sex offenders" abandon committing sex crimes when they reach maturity (Lussier et al., 2012: 1560). Contrary to practitioners and legislators groundless assumption, most of the researchers who studied versatility in offending agree that "the pure sex offender is a rarity; instead, sex offenses are single and infrequent and often are embedded in an extensive criminal history of property and violent crimes" (Simon, 2000:283).

Disagreeing with the above approaches, developmental and life-course criminologists suggest a "person-oriented approach" to understand offending patterns of sex offenders. They claim that researchers should focus on "within-individual changes in offending" by using a "longitudinal approach" in order to have an entire understanding of the "patterns of onset, course, and desistance with distinct correlates and risk factors" (Lussier et al., 2012: 1562).

To find out whether sex offenders specialize in sex crimes, Miethe, Olson \& Mitchell conducted a research "on about 10,000 sex offenders". They discovered that only a small portion of sex offenders $(5 \%)$ are categorized as "specialists or persistent" sex offenders. On the other hand, vast majority of the sex offenders $(60 \%)$ were convicted only one time "for a sex offense in their criminal careers". Thus, Meithe et al. claim that sex offenders have "low levels of specialization and persistence". However, even though only a tiny amount of sex offenders specialize, they tend to be "child molesters" and not the "rapist" opposite to the general belief (2006: 204, 222). These results were replicated by Harris et al. who examined "572 adult male sex offenders". Their research concluded that the versatility of the sex offenders was predominant, but "child molesters were significantly more likely than rapists to specialize in sexual offenses" (2009: $38,42)$.

Lussier et al. examined offending patterns of " 498 Dutch male juvenile sex offenders from age 12 to 32, who had been convicted of a hands-on sex offence or confessed to it between 1988 and 2001". As a result of following "person-oriented perspective" and focusing on "within individual" differences, their results discovered that there are two distinct groups of juvenile sex offenders: "adolescent limited" and "high-rate slow desisters". Majority of the juveniles (89.6\%) were categorized as "adolescent limited" and only 10.4\% of them were defined as "high-rate slow desisters". Thus, adolescent limited offenders commit sex crimes because of "temporary difficulties, risk taking, entitlement, and strain". This research found that even though this group of juveniles continues committing crime, they switch crime types to "nonsexual offending in adulthood". On the other hand, life persistant sex offenders who persist in committing sex offenses during their 
Eker, A., \& Mus, E. (2016). Specialization in offending: A comprehensive review of criminological theories and empirical studies. International Journal of Human Sciences, 13(1), 2295-2322. doi:10.14687/ijhs.v13i1.3760

adulthood have certain personality traits, such as "sexual preoccupation and compulsivity, hypersexuality, poor perspective taking, callousness, (adult/child) pornography use, hostility toward women, and superficial charm and grandiosity". Nevertheless, Lussier et al. claim that only half $(52 \%)$ of these "high-rate slow desisters (27 out of 52$)$ " commit merely sex crimes; thus, this small group of offenders "specializes in sex offending" and these "sex crime specialists are responsible for a higher number of sex crime events" (2012: 1565-1576).

Additionally, Lussier (2005) and Lussier \& Cale (2013) made a huge literature review on specialization in sex crimes. Hence, they found that majority of the "sex offenders do not limit themselves to sex crimes, but rather quite the contrary" (2005: 283). Sex offenders who persist in committing crimes have a tendency to commit very different types of crimes. For example, researchers found that "sex crimes represent about 4 to $14 \%$ of the entire criminal activity of rapists (2013: 453). Moreover, Lussier and Cale claim that the subgroup of sex offences determines the recommitting level of the sex crimes. For example, as mentioned above, the probability of recommitting a sex crime in the future is very low for rapists (4 to 14\%), but the probability is very high for offenders who molest boys (40\%) (2013).

Howard, Barnett \& Mann examined crime patterns of " 14,804 convicted sex offenders in England and Wales". Akin to the above results, they found that only a small portion of (a quarter of the sample) the sex offenders were arrested only for sex crimes. Moreover, they found that specialization level was high only for certain sex offense types, such as "noncontact offenses (i.e. $85 \%$ of the indecent images offenders could be defined as sexual specialists) and internet offences". However, Howard et al. warns us that these results may be misleading because the probability of detecting these crimes is very high (2013: 246-247).

Wijk et al. reached out with the conclusion that criminals who focus on committing sex crimes are heterogeneous rather than homogenous by analyzing crime patterns of "rapists and sexual assaulters $(n=57)$, child molesters $(n=55)$, and non-sex offenders: violent $(n=85)$ and nonviolent offenders $(n=80)$ ". Their research also revealed that, although all of the sex offenders have unsuccessful contacts with their friends, and have "lower score on extraversion, impulsiveness, and play truant", only the "rapists and sexual assaulters have a lower score on the IQ test and the child molesters have a higher score on neuroticism" (2005: 25, 32). Subsequently, these results show that sex offenders specialize in some subtypes of sex crimes because of their personality traits. Since they mostly suffer from "social deficits and disabilities", these traits eventually "lead to all kinds of distorted thoughts and fantasies (cognitive distortions) that may ultimately predispose committing a sex offence" (2005: 31).

Simon studied 142 child molesters, 290 violent offenders, and 51 rapists, and found that those criminals do not specialize in one type of crime, but they commit different types of crimes (2000). Simon argues that most of the studies on sex offenders show similar results. For example, Hanson \& Bussiere (1998) conducted a meta-analysis study and examined the results of 61 researches. They found that $36 \%$ of the sex offenders committed other types of crimes, while only $13 \%$ of them recommitted only sex offenses. Grunfeld \& Noriek (1986) examined offending patterns of 541 Norwegian males, who were convicted for sex crimes. They found that $24 \%$ of them were reconvicted for property crimes, $10 \%$ of them incarcerated for violent crimes, but only $13 \%$ of them were reconvicted for a new sex offense (Simon, 2000).

Simon's study shows that sex offenders are neither specialized nor mentally disordered. His study also falsified the common assumption about child molesters that they suffer from pedophilia or other type of mental disorder. Furthermore, he found that most of them have antisocial personality disorder, several criminal records about different types of crimes, and substance abuse problem (Simon, 2000).

On the other hand, Soothill et al. criticized Simon findings and claimed that sex offenders are much more specialized than they have been assumed. Their study showed that sex offenders commit same kind of sex offenses except for a small group who do not care about the gender and age of their victims. Therefore, they commit all kinds of sex offenses, but still specialize in sex 
Eker, A., \& Mus, E. (2016). Specialization in offending: A comprehensive review of criminological theories and empirical studies. International Journal of Human Sciences, 13(1), 2295-2322. doi:10.14687/ijhs.v13i1.3760

crimes (Soothill et al., 2000). Although they found support for specialization in sex offenses, they conclude their study by stating that "sex offenders may be specialists, they may be generalists, or they may be both" (Soothill et al., 2000:66).

Most of the above mentioned studies consider sex criminals who follow their unresistable instincts. However, borrowing the arguments of rational choice theory, Beauregard, Leclerc and Lussier claim that "sex offenders are rational decision makers who plan their crime on varying levels". For example, by carrying out an "in-depth interviews" with "30 rapists, 17 child molesters, and 22 victim crossovers", they found that "Child molesters clearly prefer the right environment and a cooperative victim", and prioritize "controlling the situation before acting on the victim". Whereas, "rapist make sure to protect their identity and not to leave evidence" and prioritize "controlling the victim during the crime". Moreover, Beauregard et al. claim that sex offenders give more importance to the suitability of the situation and less risky opportunities, such as "drunken female, alone, out on the street", and so on (2013: 1281, 1289).

\section{Discussion}

Up till now, we have presented hypotheses of several criminological theories and the results of numerous empirical studies to comprehensively capture the specialization and versatility in offending. Although understanding reasons for specialization and versatility is very important to find out the reasons that shape criminal strategies and to develop tailor-made effective prevention, incarceration, and rehabilitation policies (Tumminello et al., 2013). In addition, there is a vital disagreement amongst theorists and researchers whether specialization in offending is a fact or fictitious.

It will be useful to clarify offense categories prior to discussing the disagreements. Researchers generally accept Cohen's and Spelman's categorizations: "property, violent/personal, and delinquency (status) offenses". Cohen defines them as "offense clustering" (Lattimore et al., 1994: 293). In this discussion, we will focus on the offense clusters rather than focusing on a single crime, such as burglary or aggravated assault because most of the researchers examine clusters of crimes (e.g. violent vs. nonviolent).

The very first disagreement is a reflection of the lifelong debate among the criminological theories: "what causes crime?" However, some criminologists try to answer this vital question mentioning only one reason, while others indicate very diverse reasons for different crime types (Hirschi \& Gottfredson, 2003; Guerette et al., 2005). Criminologists who support the notion of "one underlying reason" for all crimes claim that because of the personality traits (low self-control), individuals cannot resist the temptation and easy pleasure of crime and commit all types of available crimes (Agnew, 2005: 42-44). Moreover, we deduce from the above researches that specialization in any type of crime requires skills, cognitive capacity, being patience, and planning ability. This is because in order to commit only one type of offense, criminals should resist the temptation and quick pleasure of other crimes, wait for the perfect target and timing, and should have sufficient skills. However, most of the researches have proved that criminals have "low self-control, impulsivity, irritability", and low IQ (Agnew, 2005: 209). From this perspective, it seems very logical that individuals who suffer from these deficits cannot have capacity for planning, waiting enough for suitable targets and opportunities, and developing skills to specialize in certain crimes and keep back themselves from committing other crimes.

On the other hand, proponents of specialization in offending claim that assumptions of differential association, learning, subculture, strain/anomie, biological, and power structure theories support specialization in offending. For example, they argue that the above mentioned personal deficits ("low self-control, impulsivity, irritability", and low IQ) do not cause versatility. In contrast, they cause violent crimes. In the light of researches, this explanation seems to be more logical to us rather than believing in what these personal deficits lead to the committing of all types of crimes, such as property crimes. As it can be seen in Agnew's general theory of crime, individuals' traits determine the scope of the personal behaviors while they interact with their immediate 
Eker, A., \& Mus, E. (2016). Specialization in offending: A comprehensive review of criminological theories and empirical studies. International Journal of Human Sciences, 13(1), 2295-2322. doi:10.14687/ijhs.v13i1.3760

environment. Furthermore, these theorists claim that individuals do not come to the world with the necessary skills and experiences to commit crimes. They associate with other peers and observe their environment, learn from others, and adjust their behaviors according to their immediate environment and perceived needs. However, joining delinquent groups which have dense networks limits available crime opportunities and motivations for committing other crimes. This is because they come together for certain purposes. Thus, they specialize in certain crimes (Cloward \& Ohlin, 2003; Sutherland \& Cressey, 2003; Jennings et al., 2014; Tumminello et al., 2013; Rowe, 2003; and Colvin \& Pauly, 1983; McGloin \& Piquero, 2010; Warr, 1996; Agnew, 2005).

However, opponents of the specialization claim that strain, social learning, differential association, and labeling theories cause versatility because interactions with other criminals will teach new crimes. In addition, spending unstructured time with them will raise new crime opportunities. This claim is supported by ample evidences. The above argument is also logical and supported by theories and researches. Based on empirical results and our 20-year long policing experiences, we claim that both explanations are true even though they seem contradictory. McGloin and Piquero have reached the most explanatory results which support both assumptions. Their research revealed that redundancy in peer groups cause specialization because they have a purpose of committing only certain crimes. Also, they do not associate with other individuals. On the other hand, less dense linkages among group members increase the chance of interacting with other delinquents, which increases versatility in offending (Thomas, 2016; McGloin \& Piquero, 2010; Mazerolle et al., 2000).

Consequently, the above explanations focus on "between-person" variations and compare one group of persons with other groups. However, life-course and developmental theorists argue that the behaviors of individuals are not monotonous and they tend to change as their personalities mature. Thus, they argue that researchers should focus on life-course of individuals and "withinperson variations" to find out whether specialization is present or not. They have two basic approaches. First, they examine the between-person variations by categorizing individuals as "adolescence-limited" and "life-course persistent" offenders. Having same arguments with the proponents of specialization, developmental theorists claim that adolescence-limited offenders commit crime with other peers for certain reasons, such as demonstrating autonomy. Thus, they specialize in offending. On the other hand, they claim that life-course persistent criminals will be more versatile because of the long-lasting personality deficits. At this point, they share the same assumptions with Gottfredson and Hirschi (Sampson \& Laub, 1993; Moffitt, 1993; Mroczek, Spiro III \& Almeida, 2003).

Second, the main argument of the developmental theories is the change of individuals because of the different factors at the different stages of lifespan. Therefore, they focus on "withinperson variations" and claim that individuals change their crime styles throughout their life-course. McGloin, Sullivan \& Piquero did an exceptional job by capturing this aspect of developmental theories in their study. They found that offenders specialize for certain periods of times because their needs, interests, and crime opportunities were more attractive and suitable for them at that limited period of time. Bushway, Sweeten, and Nieuwbeerta support this argument and claim that "the causal factors influencing development" of offenders "may shift as the individual progresses along his or her behavioral pathway" (McGloin, Sullivan \& Piquero, 2009; Piquero et al., 1999: 295; Lattimore et al., 1994; Bushway, Sweeten, \& Nieuwbeerta, 2009:260).

However, Cohen disagrees with this explanation and claims that offenders specialize in certain crimes because of the developed skills and experienced benefits. Similarly, Armstrong and Britt refuse the above claim by focusing on the same variable of Moffitt's "life-course persistent" portraying, and argue that "life-course persistent offenders" will be more specialized, not versatile. They base their claim on "stable personality traits" which is an indisputable empirical fact. They argue that constant personality traits make one type of crime more attractive to please habitual personality needs and the desires of individuals. Researchers found two conflicting results by using same factor. Thus, we want to draw the attentions on "recurring personality needs" and stability of 
Eker, A., \& Mus, E. (2016). Specialization in offending: A comprehensive review of criminological theories and empirical studies. International Journal of Human Sciences, 13(1), 2295-2322. doi:10.14687/ijhs.v13i1.3760

"personality traits throughout life course". Does an offender have same level of traits and needs when he is 10, 15, 25 or 50 years old? Moffitt argue that this is not the case because she found that these habitual offenders start "bitting and hitting at age 4, shoplifting at truancy at age 10, stealing at age 16, robbery and rape at age 22, fraud and child abuse at age 30 and embezzlement at work". Moreover, several researchers found that as the age of the offenders increase, so does the tendency of making rational choices increase by narrowing crime types to low risk and high gain. Arguments of the proponent of versatility seem to be more consistent (Armstrong \& Britt, 2004: 847; Moffitt, 2003: 452; Piquero et al., 1999).

On the other hand, Richards et al. suggest "a combination of specialized and generalized criminal behaviors". Several researchers join this argument via finding offenders that is specialized in certain crimes "temporally". Examining "specialization across ages", researchers found that there is high "diversity at early adolescence and adulthood", but diversification decreases by age and specialization increases. Moreover, researchers found that older criminals concern more on monetary needs. Thus, they specialize in instrumental crimes (Richards et al., 2014: 646; Nieuwbeerta et al., 2010:19; Tumminello et al., 2013; Blumstein et al., 1988; Youngs, Ioannou \& Eagles, 2014). Evidencing whether offenders' constant personality deficits cause specialization or versatility, and whether they shift their specialization focus as they get older or not, needs more longitudinal studies which can truly capture the behavioral patterns of "life-course persistent offenders".

Even though it is a general fact that females commit far less crime than males, researchers also examined whether being female or male have any effect on crime specialization. Thus, two general findings emerge from the empirical studies. First, females generally commit less serious and nonviolent crimes, such as "embezzlement, prostitution, runaway offenses, fraud, forgery, disorderly conduct, and liquor". Researchers claim that females have more tendency than males to specialize in the above listed crimes. For example, research of Farrington, Snyder and Finnegan revealed that almost half of the female offenders were specialist. Second, opponent of this view claim that neither of the genders specializes in offending. For example, Hindelang found that female are more versatile than males. The first argument seems more robust because studies found that "direct control and supervision" of parents on girls are much higher than males. Studies also found that females' participation in unstructured activities is less often compared to males. Thus, they have limited crime opportunities and focus on the above crimes. However, 7 crimes were listed above. Do females specialize in either one or do they swing among them? If they commit all of them, can we categorize this committing pattern as specialization because they commit only one cluster of crimes? Accepting Cohen's "offense clustering" approach and assessing this tendency as specialization is reasonable because they are within the same cluster. However, Mazerolle et al. disagree with this conclusion and claim that "female diversity" is robust. Furthermore, researchers generally fail to detect changes "between the property and other adult status offenses", such as prostitution. Although they highlighted a good point, they did not mention the proportion of the females who switch between property crimes, and prostitution. Further researches should clarify this debate (Vold, Bernard \& Snipes, 2002: 276; Becker \& McCorkel, 2011: 7-24; Osgood et al., 1996: 649; Farrington, Snyder \& Finnegan, 1998: 478, 483; Hindelang, 1971: 523).

Researchers have spent great amount of endeavor on violent and nonviolent crimes in terms of specialization debate. Hence, there are two main debates amongst criminologists. Some of them claim that causal factors for both types of crimes are same; thus, offenders commit both of them and do not specialize in either one. For example, Andresen and Linning found an interesting point as shown in Table 1. Their research revealed that unemployment and low income cause both violent and nonviolent crimes through different processes. On the other hand, vast majority of the researchers found that criminals specialize in either type of crimes for different reasons. Opponents of specialization argue that differences in personality traits, parenting and family disciplinary styles, social status, and social environment incline offenders to select either type of crime. Since vast majority of the empirical studies support this argument, it can be concluded that 
Eker, A., \& Mus, E. (2016). Specialization in offending: A comprehensive review of criminological theories and empirical studies. International Journal of Human Sciences, 13(1), 2295-2322. doi:10.14687/ijhs.v13i1.3760

offenders are forced and/or motivated by internal and external factors to focus on either crime type (Andresen \& Linning, 2015; Youngs, Ioannou \& Eagles, 2014; Lynam, Piquero \& Moffitt, 2004; Osgood \& Pauly, 1983; Tumminello et al., 2013).

Hence, since most of the researches support the specialization in either violent or nonviolent crimes, the second debate arises with this assumption: do criminals specialize in violent or nonviolent crimes, and why? Researchers found that personality traits, needs of the individuals, and the culture of the immediate environment such as family and neighborhood motivate offenders' decisions to attack persons or properties. For example, some researchers claim that individual insufficiencies, such as "low self-control, impulsiveness, aggressiveness and being irritable" cause specialization in violent crimes. Moreover, studies found that offenders who live in disadvantaged neighborhoods with a "conflict culture", and who belong to "lower class workers" experience more violence. Thus, they specialize in violent crimes. On the other hand, professionals, white-collar workers, and high income offenders specialize in nonviolent crimes since their immediate environment do not generate violence. Researchers also found that older offenders are motivated more on property crimes because of increased monetary concerns (Agnew, 2005: 140141; Tumminello et al., 2013: 1; Mazerolle et al., 2000; Colvin \& Pauly, 1983; Nieuwbeerta et al., 2010).

These results regarding specialization in violent and nonviolent crimes are convincing and robust. However, by borrowing the arguments of strain/anomie theories, we claim that researchers should focus more on the effect of "American Dream" on disadvantaged offenders. Although most of the researches found that they focus on violent crimes, other researchers found that they commit property crimes to satisfy their perceived needs. Moreover, a recent research of Andresen and Linning found that offenders that commit both crimes ate at the same time because of the same economic factors surrounding them (Merton, 2003; Rosenfeld \& Messner, 2003; Andresen \& Linning, 2015). Therefore, we argue that there are ample reasons derived from previous studies to claim that offenders will commit both of them at the same time with the exception of criminals who suffer from biological deficits. More comprehensive and longitudinal studies should focus on this argument.

Another discussion has been continuing on offending patterns of sex criminals. It is undoubtably believed by the public and by policy makers that sex offenders are prone to biological and mental problems. Thus, they have perennial motivations to commit sex crimes. However, almost all of the empirical studies found that "pure sex offender is a rarity". For example, Lussier et al. found that only $10.4 \%$ of the sex offenders can be categorized as "high-rate slow desisters", and only half of them (5\% of all sex offenders) specialize in sex crimes because of personality deficits, such as "sexual preoccupation and compulsivity, hypersexuality", and so on. Moreover, researches examined in this paper revealed two important results. First, rapists whom people are mostly terrified about do not specialize in sex crimes. Second, vast majority of the delinquents who commit most of the crimes desist from committing sex crimes as they mature.

However, even though empirical studies found out that a small group of sex offenders specialize in sex crimes, we cannot ignore them by looking at their low proportion because they are responsible for most of the sex crimes. Furthermore, researchers found that child molesters (especially boy molesters) specialize in their crime. In addition to child molesters, "noncontact" sex offenders specialize in sex crimes (e.g. "adult/child pornography and indecent images") with the help of technological opportunities. On the other hand, Beauregard, Leclerc and Lussier mention a promising outcome as a result of their "in-depth interviews" with "30 rapists and 17 child molesters". They claim that child molesters and rapists make rational choices and look for suitable environments and victims. This study has two important aspects. Researchers should follow "person-oriented approach" and carry out "in-depth interviews" with both offenders and victims to fully understand the patterns of offending and victimization. Another important result is that even though sex offenders suffer from personality traits, they make rational calculation. Thus, policy makers, law enforcement officials, and especially families should closely protect their children, 
Eker, A., \& Mus, E. (2016). Specialization in offending: A comprehensive review of criminological theories and empirical studies. International Journal of Human Sciences, 13(1), 2295-2322. doi:10.14687/ijhs.v13i1.3760

especially the females. However, as mentioned in the section of gender effect, families dedicate most of their direct control to girls, not to boys. Furthermore, findings of empirical researches warn us that boys are more dangerous than girls in terms of child molesters. Therefore, boys should be protected closely. However, we are not claiming that sex crimes against boys are more than girls. This important debate is out of the scope of this paper, but it should be clarified by other studies to prevent victimization of both boys and girls (Simon, 2000:283; Lussier et al., 2012: 1565-1576; Howard et al., 2013: 246-247; Lussier \& Cale, 2013; Beauregard, Leclerc \& Lussier, 2013: 1281, 1289).

\section{Recommendations for Future Research}

Researchers argue that simply focusing on whether criminals specialize in offending is not sufficient. They recommend that specialization researches would make more contributions to policy makers and practitioners if they focus on understanding why or why not specialization occur rather than only determining whether it exists (Guerette et al., 2005).

Results of empirical studies show that some types of offenses are more attractive to some offenders. Discovering underlying reasons why certain types of crimes are more or less attractive for certain types of criminals will increase the possibility of predicting future criminal behaviors and type of offenses. Forecasting future crimes and their types can help practitioners to develop more effective crime prevention policies and treatment programs. Thus, scholars recommend that "theory-driven researches" should be conducted (Bouffard et al., 2008: 588). In other words, criminological theories, such as "control, strain, and social learning" should shed light on the way of the researchers by making more explanation on why some types of offenses are more attractive to some offenders (Armstrong \& Britt, 2004; Mazerolle et al., 2000; Osgood \& Schreck, 2007).

Moreover, theories should focus on the clarify of motives as to "why there is more specialization in some offenses than others, and why specialization tends to increase with successive offenses". Also, it should explain the whole causal relationships between specialization and "age of onset, career length, and offending rates" (Farrington et al., 1988:483). Moreover, future studies should focus on the stability and desistance in specialization because if specialization in certain type of crime is stable, "predicting who will specialize" and in which crime, will be too vital for crime prevention policies (Osgood \& Schreck, 2007: 301). In this regard, Lussier et al. advise that future research should focus on clarifying the reasons why some offenders desist from committing crimes (2012). Finding out those factors are very important because they compose of the "constraints against crime" (Agnew, 2005: 37). Thus, intervention programs try to impose those factors to other criminals who continue offending (Lussier et al., 2012).

As can be seen from the above conflicting results and discussions, human behavior is too complex (McGloin \& Piquero, 2010). Thus, the characteristics and behaviors of individuals are not static, but dynamic (Lussier et al., 2012). Therefore, future studies "take an individual-centered rather than a variable-centered approach" to understand the behaviors of persons (Lynam et al., 2004; 226). Moreover, Armstrong and Britt claim that research on specialization should use "individual level data" because "results of aggregate analyses may lead to a false impression about offense type patterns" (2004; 871).

Additionally, researchers and theorists, especially the developmental and life course theorists should describe the causal relations and interactions amongst individual developments, personal and external factors, decision making process, and in committing a specific type of crime (Sampson \& Laub, 1993; Moffitt, 1993; Agnew, 2005). Moreover, Lussier claims that "generality and specialization can co-occur within the same criminal career". Thus, it is suggested that specialization research should consider the "stability and change" through lifespan (2005: 284).

Researchers who study specialization try to capture whether offenders continue to commit same type of crime or "cluster of similar crimes" (Tumminello et al., 2013: 6). Therefore, "coding and classification of offenses within general crime categories" is extremely important to detect 
Eker, A., \& Mus, E. (2016). Specialization in offending: A comprehensive review of criminological theories and empirical studies. International Journal of Human Sciences, 13(1), 2295-2322. doi:10.14687/ijhs.v13i1.3760

repeated offenses. For this reason, researchers should make "mutually exclusive" definitions of crime categories (Miethe et al., 2006; 223).

Researchers give huge attention to the quality and comprehensiveness of the data to reach accurate results. For example, Lynam et al. claim that "conclusions drawn from studying specialization may vary across self-report and official records". Thus, they recommend that future studies should analyze both official and self-report data sets "to provide a more accurate portrayal" of specialization in offending $(2004 ; 226)$. Conducting "in-depth interviews" with criminals and their preys help researchers to entirely comprehend why and how criminals decided to select an individual as a victim. Results of this approach will help in designing proactive "target hardening" crime prevention programs (Beauregard et al., 2013).

Moreover, Gottfredson and Hirschi point out an important problem of crime data by claiming that researchers tend to "focus on most serious crimes in series of events" and official's record is regarded as the most serious crimes. Thus, they assert that proponents of specialization in crime ignore several least serious crimes committed by the same person, and conclude that there is "great variability in the kinds of criminal acts" (2003: 244-247). Therefore, future studies should be careful on capturing the least serious crimes and should not ignore self-report data to "include those crimes that do not come to the attention of authorities (Lussier, 2005: 283). Osgood and Schreck also claim that researchers should use large samples and powerful statistical methods to reach significant results (2007).

Finally, Turkish researchers have not conducted adequate research on crime specialization yet. Therefore, they should carry out more researches in order to map out the offending patterns of Turkish adult criminals and delinquents.

\section{Conclusion and Policy Recommendations}

Results of empirical studies which examined specialization in offending, shows that the widespread assumption of legislators and practitioners according to which criminals specialize in certain types of offenses is not true. However, the opposite perception which totally reject specialization in offending is also not true, and "premature" (Kempf, 1987). Most of the above mentioned empirical studies demonstrate that there is a small specialization in huge versatility. Although their degrees are different, we can conclude that both assumptions are true.

In this regard, Rojek and Ericson made an exceptional determination regarding stability and desistance in offending. Thus, they claim that offending patterns of delinquents can be defined as "cafeteria style". They commit many different types of crimes, and most of them stop committing crimes when they reach age 28 (Moffit, 1993). However, treatment and intervention programs are designed as if all delinquents will have long criminal careers; thus, since these programs cannot accurately capture the nature of delinquency, their effects on reducing juvenile crime will be very limited (1982; 26-27).

For example, if we examine the violent, nonviolent, and sex offenders`crime patterns, we will notice that they commit wide variety of crimes (Piquero, 2000; Simon, 2000). On the other hand, some of those criminals exhibit specialization patterns (Piquero et al., 1999; Soothill et al., 2000). We also observe both versatility and specialization in offending for those criminals who start committing crimes at their earlier ages (Piquero et al., 1999; Armstrong \& Britt, 2004). Therefore, researchers, legislators, and practitioners should compose their studies, policies, and law enforcement strategies by considering these offending patterns. This is because any research or strategy based on either assumption will have less impact in the presence of opposite offense patterns (Lattimore et al., 1994). 
Eker, A., \& Mus, E. (2016). Specialization in offending: A comprehensive review of criminological theories and empirical studies. International Journal of Human Sciences, 13(1), 2295-2322. doi:10.14687/ijhs.v13i1.3760

\section{References}

Agnew, R. (2005). Why Do Criminals Offend? A General Theory of Crime. Los Angeles: Roxbury Publishing.

Andresen, M. A. and Linning, S. J. (2015). Unemployment, businesscycles, and crime specialization: Canadian provinces, 1981-2009. Australian \& New Zealand Journal of Criminology. Vol. 0(0) 119.

Anthony, J. \& Petronis, K. R. (1995). Early-onset drug use and risk later drug problems. Drug and Alcohol Dependence 40: pp. 9-15.

Armstrong, T. A. and Britt, C. L. (2004). "The Effect of Offender Characteristics on Offense Specialization and Escalation”. Justice Quarterly, 21 (4) pg. 844.

Beauregard, E., Leclerc, B. \& Lussier, P. (2012). Decision making in the Crime commission process: Comparing Rapists, Child Molesters, and Victim-Crossover Sex Offenders. Criminal Justice and Behavior, Vol. 39 No. 10: 1275-1295.

Becker, S. \& McCorkel, J. A. (2011). The Gender of Criminal Opportunity: The Impact of Male CoOffenders on Women's Crime. Feminist Criminology Vol. 20 (10):1-32.

Blumstein, A., Cohen, J., Das, S. \& Moitra, S. D. (1988).Specialization and Seriousness During Adult Criminal Careers. Journal of Quantitative Criminology, Vol. 4: 4.

Blumstein, A., Cohen, J., Roth, J. A., and Visher, C. A., eds. (1986).Criminal Careers and Career Criminals. Washington, DC: National Academy Press.

Bouffard, L. A., Wright, K. A., Muftic, L.R. \& Bouffard, J. A. (2008) Gender differences in specialization in intimate partner violence: comparing the gender symmetry and violent resistance perspectives. Justice Quarterly 25:570-594

Brennan, P., Mednick, S. \&John, R. (1989). Specialization in violence: evidence of a criminal subgroup. Criminology Vol.27: 3.

Britt, C. L. (1996). "The Measurement of Specialization and Escalation in the Criminal Career: An Alternative Modeling Strategy". Journal of Quantitative Criminology, Vol: 12 (2): 193-222.

Bureau of Justice Statistics. Reentry Trends in the U.S.. Retrieved April 08, 2012 from http://www.ojp.usdoj.gov/bjs/reentry/recidivism.htm

Burnett, R., \& McNeill, F. (2005).The place of the officer-offender relationship in assisting offenders to desist from crime.Probation Journal, 52(3), 221-242.

Bushway, Shawn D., Sweeten, G. \& Nieuwbeerta, P. (2009) Measuring Long Term Individual Trajectories of Offending Using Multiple Methods Journal of Quantitative Criminology 25:259-286

Caspi, A., \& Moffitt, T. E. (1995). The continuity of maladaptive behavior: From description to understanding in the study of antisocial behavior. In D. Cichetti \& D. Cohen (Ed.).Manual of developmental psychology (pp. 472-511). New York: John Wiley.

Chesney-Lind, M. \& Faith, K. (2001).What about feminism? Engendering Theory-Making in Criminology .In Paternoster, R and Bachman, R. (Ed.).Explaining Criminals and Crime: Essays in Contemporary Criminological Theory. Los Angeles, California: Roxbury Publishing.

Cloward, R. A. \& Ohlin, L. E. (2003).Delinquency and Opportunity. In Cullen, F. T. \& Agnew, R. (Ed.). Criminological Theory: Past to Present: Essential Readings. Los Angeles: Roxbury Publishing.

Colvin, M. \& Pauly, J. (1983). A Critique of Criminology: Toward an Integrated Structural-Marxist Theory of Delinquency: American Journal of Sociology, Vol. 89, No. 3: 513-551.

Cornish, D. B. \& Clarke, R. V. (1989).Crime Specialisation, Crime Displacement and Rational Choice Theory. In H. Wegener et al. (eds.), Criminal Behavior and the Justice System. Springer-Verlag New York Inc.

Cullen, F. T. and Agnew, R. (2003). (Ed.). Criminological Theory: Past to Present: Essential Readings. Los Angeles: Roxbury Publishing.

DeLisi, M. (2003). The Imprisoned Nonviolent drug offender: Specialized Martyr or Versatile Career Criminal? American Journal of Criminal Justice, Vol. 27 No. 2, 
Eker, A., \& Mus, E. (2016). Specialization in offending: A comprehensive review of criminological theories and empirical studies. International Journal of Human Sciences, 13(1), 2295-2322. doi:10.14687/ijhs.v13i1.3760

DeLisi, M., Beaver, Kevin M., Wright, Kevin A., Wright, John P., Vaughn, Michael G. \& Trulson, Chad R. (2011). Criminal Specialization Revisited: A Simultaneous Quantile Regression Approach. American Journal of Criminal Justice 36:73-92.

Farrington, D. P. (2003). Developmental and life-course criminology: Key theoretical and empirical issues- The 2002 Sutherland award address. Criminology, 41(2), 221- 256.

Farrington, D. P., Snyder, H. N., \& Finnegan, T. A. (1988). Specialization in juvenile court careers. Criminology, 26 (3), 461-488.

Gfroerer, J. C., Wu, L.-T., \& Penne, M. A. (2002).Initiation of Marijuana Use: Trends, Patterns, and Implications. (Analytic Series: A-17, DHHS Publication No. SMA 02-3711).

Gottfredson, M. R. \& Hirschi, T. (1990). A general theory of crime. Stanford University Press, Stanford.

Gottfredson, M. R. and Hirschi, T. (2003). A General Theory of Crime. In Cullen, F. T. and Agnew, R. (Ed.). Criminological Theory: Past to Present: Essential Readings. Los Angeles: Roxbury Publishing.

Guerette, R. T., Stenius, V. M. K. \& McGloin, J. M. (2005). "Understanding offense specialization and versatility: A reapplication of the rational choice perspective" Journal of Criminal Justice Vol. 33 pg. $77-87$

Harris, D. A., Smallbone, S., Dennison, S. \& Knight, R. A. (2009). Specialization and versatility in sexual offenders referred for civil commitment. Journal of Criminal Justice, Vol. 37.

Hawkins, J., Catalano, R. \& Miller, J. (1992).Risk and Preventive factors for alcohol and other drug problems in adolescence and early adulthood: Implications for substance abuse prevention. Psychological Bulletin, 112, 64-105.

Hindelang, M. J. (1971). Age, Sex, and the Versatility of Delinquent Involvements. Social Problems, 18(4): 522-535.

Hirschi, T., \& Gottfredson, M. R. (1995). Control theory and the life-course perspective. Studies on Crime and Crime Prevention, 4, 131-142.

Howard, P. D., Barnett, G. D. \& Mann, R. E. (2013).Specialization In and Within Sexual Offending in England and Wales. Sexual Abuse: A Journal of Research and Treatment, Vol. 26: 225.

Jennings, Wesley G., Zgoba, Kristen M., Donner, Christopher M., Henderson, Brandy B. \& Tewksbury, Richard (2014). Considering specialization/versatility as an unintended collateral consequence of SORN. Journal of Criminal Justice 42: 184-192.

Kempf, K. L. (1987). "Specialization and the Criminal Career."Criminology, Vol. 25 pg. 399-420.

Klein, M. (1984). "Offense Specialization and Versatility among Juveniles". British Journal of Criminology Vol. 24 pg.185-94.

Lattimore, P. K., C. A. Visher, and R. Linster. (1994). "Specialization in Juvenile Careers: Markov Results for a California Cohort.” Journal of Quantitative Criminology Vol. 10 pg. 291-316.

Laub, J. H., \& Sampson, R. J. (2004). Strategies for bridging the quantitative and qualitative divide: Studying crime over the life course. Research in Human Development, 1(1\&2), 81-99.

Laub, J. H., \& Sampson, R. J. (2003).Shared Beginnings, Divergent Lives: Delinquent Boys to Age 70.Cambridge: Harvard University Press.

Le Blanc, M., \& Loeber, R. (1998). Developmental criminology updated. In M. Tonry (Ed.), Crime and justice: A review of research (Vol. 23, pp. 115-198). Chicago: University of Chicago Press.

Lussier P (2005) The criminal activity of sexual offenders in adulthood: revisiting the specialization debate. Sexual Abuse: A Journal of Research and Treatment, Vol. 17, No. 3:269-292

Lussier, P., Berg, C. V. D., Bijleveld, C. \& Hendriks, J. (2012). A Developmental Taxonomy of Juvenile Sex Offenders for Theory, Research, and Prevention: The Adolescent-Limited and the High-Rate Slow Desister. Criminal Justice and Behavior, Vol. 39, No. 12: 1559-1581.

Lussier, P. \& Cale, J. (2013). Beyond sexual recidivism: A review of the sexual criminal career parameters of adult sex offenders. Aggression and Violent Behavior, 18:445-457.

Lynam, D. R., Piquero, A. R., \& Moffitt, T. E. (2004). Specialization and the Propensity to Violence: Support from Self-Reports but not Official Records. Journal of Contemporary Criminal Justice, Vol. 20 No. 2: 215-228. 
Eker, A., \& Mus, E. (2016). Specialization in offending: A comprehensive review of criminological theories and empirical studies. International Journal of Human Sciences, 13(1), 2295-2322. doi:10.14687/ijhs.v13i1.3760

Mazerolle, P., Brame, R., Paternoster, R., Piquero, A., \& Dean, C. (2000). Onset age, persistence, and offending versatility: comparisons across gender. Criminology, 38(4), 1143-1172.

Merton, R. K. (2003). Social Structure and Anomie. In Cullen, F. T. and Agnew, R. (Ed.). Criminological Theory: Past to Present: Essential Readings. Los Angeles: Roxbury Publishing.

Rosenfeld, R. \& Messner, S. F. (2003). Crime and the American Dream. In Cullen, F. T. and Agnew, R. (Ed.). Criminological Theory: Past to Present: Essential Readings. Los Angeles: Roxbury Publishing.

Miethe, T. D., Olson, J. \& Mitchell, O. (2006). Specialization and Persistence in the Arrest Histories of Sex Offenders: A Comparative Analysis of Alternative Measures and Offense Types. Journal of Research in Crime and Delinquency, Volume 43 Number 3: 204-229.

McGloin, J. M., Sullivan, C. J. \& Piquero, A. R. (2009). Aggregating to versatility? Transitions among offender types in the short term. British Journal of Criminology, Vol.49:243-264.

McGloin, J. M., \& Piquero, A. R. (2010). On the relationship between co-offending network redundancy and offending versatility. Journal of Research in Crime\& Delinquency,Vol.47: 6390 .

McGloin, Jean M., Sullivan, Christopher J., Piquero, Alex R., Blokland, A. \& Nieuwbeerta, P. (2011). Marriage and offending specialization: Expanding the impact of turning points and the process of desistance. European Journal of Criminology 8(5) 361-376.

Moffitt, T. E. (1993). Adolescent-limited and life-course-persistent antisocial behavior: A developmental taxonomy. Psychological Review, 100, 674-701.

Moffitt, T. E., \& Caspi, A. (2001). Childhood predictors differentiate life-course persistent and adolescence-limited antisocial pathways among males and females Development and Psychopathology, 13, 355-375.

Moffitt, T. E. (2003). Pathways in the Life Course to Crime. In Cullen, F. T. and Agnew, R. (Ed.). Criminological Theory: Past to Present: Essential Readings. Los Angeles: Roxbury Publishing.

Mroczek, D. K., Spiro III, A. \& Almeida, D. M. (2003).Between- and within-person Variation in affect and Personality over days and years: how basic and applied approaches can inform one another. Ageing International, Vol. 28, No. 3: 260-278.

Mus, E. and Eker, A. (2011).An Analysis of Life Course Theories. Journal of Police Sciences, Vol:13 (3): 147-166.

Nieuwbeerta, P., Blokland, A. A.J., Piquero, A. R. \& Sweeten,G.(2010). A Life Course Analysis of Offense Specialization across Age: Introducing a New Method for Studying Individual Specialization Over the Life Course. Crime and Delinquency20(10) 1-26.

Osgood, D. W., Wilson, J. K., O'Malley, P. M., Bachman, J. G. \& Johnston, L. D. (1996).Routine Activities and Individual Deviant Behavior. American Sociological Review, Vol. 61, No. 4: 635655.

Osgood, D. W. \& Schreck, C. J. (2007). A new method for studying the extent, stability, and predictors of individual specialization in violence. Criminology Vol.45:2.

Paternoster, R., Brame, R., Piquero, A., Mazerolle, P., Dean, C. (1998). "The forward specialization coefficient: Distributional properties and subgroup differences". Lournal of Quantitative Criminology. New York: Jun Vol.14, Iss. 2 pg. 133

Piquero, A.(2000). Frequency, Specialization, and Violence in Offending Careers. Journal of Research in Crime and Delinquency. Vol. 37 No. 4, Nov. 392-418.

Piquero, A., Paternoster, R., Mazerolle, P., Brame, R., \& Dean, C.W. (1999).Onset age and specialization. Journal of Research in Crime and Delinquency, 36, 275-299.

Piquero, A. R., Farrington, D. P. \& Blumstein, A. (2003). The Criminal Career Paradigm Crime and Justice, Vol. 30: 359-506. 
Eker, A., \& Mus, E. (2016). Specialization in offending: A comprehensive review of criminological theories and empirical studies. International Journal of Human Sciences, 13(1), 2295-2322. doi:10.14687/ijhs.v13i1.3760

Richards, Tara N., Jennings, Wesley G. Tomsich, Elizabeth A. and Gover, Angela R. (2013). A Longitudinal Examination of Offending and Specialization Among a Sample of Massachusetts Domestic Violence Offenders. Journal of Interpersonal Violence 28(3) 643-663.

Rojek, D. G. and Ericson, M. L. (1982). Delinquent careers: A test of the career escalation model. Criminology. Vol. 20:5- 28.

Rove, D. (2003). Does the Body Tell? Biological Characteristics and Criminal Disposition. In Cullen, F. T. and Agnew, R. (Ed.). Criminological Theory: Past to Present: Essential Readings. Los Angeles: Roxbury Publishing.

Sampson, Robert J. \& Laub, John H. (1993).Crime in the Making: Pathways and Turning Points Through Life. Harvard University Press, Cambridge, MA.

Simon, L. M. J. (2000). "An Examination of the Assumptions of Specialization, Mental Disorder, and Dangerousness in Sex Offenders". Behavioral Sciences and the Law Vol. 18 pg. 275-308.

Soothill, K., Francis, B., Sanderson, B., and Ackerley, E. (2000). "Sex Offenders: Specialists, Generalists, or Both?” British Journal of Criminology Vol. 40pg. 56.

Sutherland, E. H. \& Cressey, D. R. (2003). A Theory of Differential Association. In Cullen, F. T. \& Agnew, R. (Ed.). Criminological Theory: Past to Present: Essential Readings. Los Angeles: Roxbury Publishing.

Sykes, Gresham M. \& Matza, David.(2003). Techniques of Neutralization. In Cullen, F. T. \& Agnew, R. (Ed.). Criminological Theory: Past to Present: Essential Readings. LosAngeles: Roxbury Publishing.

Tewksbury, R., Jennings, Wesley G. \&Zgoba, Kristen M. (2012).A longitudinal examination of sex offender recidivism prior to and following the implementation of SORN.BehavioralS ciencesandtheLaw, Vol.30: 308-328.

Thomas, K. J. (2016). On the Relationship Between Peer Isolation and Offending Specialization: The Role of Peers in Promoting Versatile Offending. Crime and Delinquency Vol. 62 No. 1: 26-53.

Thornberry, T. P. (1987). Toward an Interactional Theory of Delinquency. Criminology, 25: 863-892.

Tumminello, M, Edling, C., Liljeros F., Mantegna R. N., \& Sarnecki, J. (2013) The Phenomenology of Specialization of Criminal Suspects. PLoS ONE 8(5): e64703. doi:10.1371/journal.pone.0064703.

Vold, G. B., Bernard, T. J., \& Snipes, J. B. (2002).Theoretical Criminology. New York: Oxford University Press.

Warr, M. (1996). Organization and Instigation in Delinquent Groups. Criminology Vol.34 No:1.

Wijk, A. v., Horn, J. v., Bullens, R., Bijleveld, C. \& Doreleijers, T. (2005) Juvenile Sex Offenders: A Group on its Own? International Journal of Offender Therapy and Comparative Criminology, 49(1).

Youngs, D., Ioannou, M. \& Eagles, J. (2014). Expressive and Instrumental Offending: Reconciling the Paradox of Specialization and Versatility International Journal of Offender Therapy and Comparative Criminology, 1-26. 